\title{
LA DENOMINACIÓN DE TIPOS, SERIES Y UNIDADES DOCUMENTALES EN ESPAÑA. APORTACIÓN A LA TEORÍA ARCHIVÍSTICA (1) ${ }^{1}$
}

\section{THE DESIGNATION OF DOCUMENTARY TYPES, SERIES AND UNITS IN SPAIN. A CONTRIBUTION TO ARCHIVAL THEORY (1)}

\author{
Mariano GARCÍA RUIPÉREZ \\ Archivo Municipal de Toledo \\ Universidad de Castilla-La Mancha
}

Resumen: La identificación documental se basa en la descripción y ésta se concreta en la denominación. El nombre dado a las distintas agrupaciones documentales tendrá una gran incidencia en las funciones archivísticas. Partiendo de esta premisa se estudian en este trabajo las aportaciones teóricas realizadas en España sobre la denominación de los tipos, series y unidades documentales. El estado de la cuestión ofrecido pretende delimitar un concepto tan esencial en Archivística como es el de tipo documental.

Palabras clave: Teoría Archivística, Agrupaciones documentales, Niveles de descripción, Tipología documental, Unidades documentales, Documentos, Denominación, Normalización.

Abstract: The identification of archival records depends on description, being this last process summed up in designation. The title given to different groups of documents will have a great incidence in archival functions. Taking this premise as our starting point, this paper presents theoretical contributions made in Spain related to designation of documentary types, series and units. The status of the issue presented here tries to delimitate the concept of "documentary typology", essential for Archival Science.

Keywords: Archival theory, Documentary groups, Description levels, Records typology, Documentary units, Records, Designation, Normalisation.

\footnotetext{
${ }^{1}$ Este texto inédito fue presentado en el Seminario "Dar nome aos documentos: da teoría à práctica" celebrado en Sao Paulo (Brasil) en octubre de 2013. Dada su extensión se publicará en dos partes. Esta primera abarca los cinco puntos primeros en los que está dividido su contenido, tal y como refleja el Índice recogido a continuación.
} 
"El nombre del tipo documental es dato indispensable a la hora de dar nombre a la unidad documental y también para dar nombre a la serie integrada por documentos del mismo tipo, que en este caso adopta el nombre del tipo documental" 2 .

\section{ÍNDICE:}

1. Las agrupaciones documentales en España.

2. Tipo documental: Un concepto básico en la descripción de unidades y series documentales.

3. El tipo documental en las descripciones anteriores a la $\operatorname{ISAD}(\mathrm{G})$.

4. El tipo documental en las actuales normas de descripción españolas.

5. El tipo documental: Delimitación del concepto.

6. El tipo documental: Clasificación y denominación. O cómo poner puertas al mar.

7. Modelos de análisis de tipos y series documentales.

8. La denominación de series y unidades documentales.

Hemos querido empezar este texto con esta frase de la doctora Antonia Heredia que de una manera tan clara define la importancia de la adecuada denominación de los documentos y el papel que en ello tiene el concepto de tipo documental. Las series documentales están en la base del quehacer archivístico y, para su definición, el tipo es un elemento básico que contribuye sobremanera a su diferenciación y clasificación. Pero, es más, como ha indicado Javier Barbadillo, "la archivística, en realidad, no clasifica documentos sino las descripciones de los documentos" 3 y en ellas juega un papel fundamental su denominación o intitulación en la medida en que en ésta se condensan sus características.

Una adecuada identificación de las unidades documentales, y de las agrupaciones en las que se integran, solo es factible si tenemos claros los elementos que utilizamos para su denominación. Nuestra intención es detenernos en la manera en la que han sido y son denominadas las agrupaciones documentales en las que clasificamos los documentos de un fondo, fijándonos especialmente en la situación española. Recordemos ahora el concepto de "fondo" aportado por A. Heredia co-

\footnotetext{
2 A. HEREDIA HERRERA, Lenguaje y vocabulario archivísticos: algo más que un diccionario, Sevilla, 2011, p. 176.

3 J. BARBADILLO ALONSO, “Apuntes de clasificación archivística”, Legajos. Cuadernos de investigación archivística y gestión documental, 10 (2007), p. 31.
} 
mo "conjunto orgánico de documentos procedente de una institución, colectivo o persona, testimonio y prueba de su respectiva gestión"

Como sabemos, la Norma $I S A D(G)$ estableció veintiséis elementos estructurados en siete áreas de información descriptiva de los que solo seis debían utilizarse en todos los casos: código de referencia, título, productor, fechas, extensión de la unidad de descripción y nivel de descripción ${ }^{5}$. Y, sin duda, es el campo "Título" el que tiene una relación directa con el tema que nos ocupa ya que el objetivo de este campo es "denominar la unidad de descripción” ¿Pero a qué unidades de descripción nos estamos refiriendo?

\section{LAS AGRUPACIONES DOCUMENTALES EN ESPAÑA}

Estas últimas han ido cambiando desde la publicación de la versión española de la Norma $\operatorname{ISAD}(G)$ en el año 2000. Entonces se reconocieron, como niveles de organización, los de fondo, subfondo, serie, subserie, unidad documental compuesta y unidad documental simple, admitiendo la posibilidad de incluir otros niveles intermedios si se consideraban necesarios. En la Norma española de descripción archivística (NEDA), publicada en diciembre de 2005, se contemplaron los siguientes niveles: fondo / colección / grupo de fondos; $1^{\mathrm{a}}$ división de fondo;

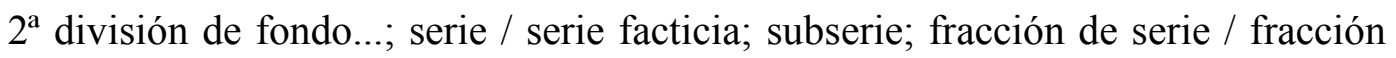
de subserie; unidad documental compuesta; unidad documental simple; y el elemento de descripción asociado ${ }^{6}$. Por último, en el texto titulado Modelo conceptual de descripción archivística y requisitos de datos básicos de las descripciones de documentos de archivo, agentes y funciones, presentado por la CNEDA como borrador final en junio de 2011, se han distinguido, como subtipos del tipo entidad documento de archivo, entre el grupo de fondos, el fondo, la división de fondo o división de grupo de fondo, la serie, la subserie, la fracción de serie o fracción de

${ }^{4}$ A. HEREDIA HERRERA, ¿Qué es un archivo?, Gijón, 2007, p. 30. En esta obra, nuestra maestra hace una clara distinción entre "archivo", escrito con minúscula, definido como el "contenido documental del Archivo, identificado con todos los documentos conservados en él, ya sea de un solo fondo o varios", y Archivo, con mayúscula, que es la "institución que conserva, trata y sirve los documentos de archivo que guarda".

${ }^{5} \operatorname{ISAD}(G)$ : Norma internacional general de descripción archivística, $2^{\mathrm{a}}$ ed., Madrid, 2000, p. 15.

${ }^{6}$ Norma española de descripción archivística (NEDA) $1^{a}$ versión, Madrid, [2005], p. 33 del Elemento "Nivel de descripción". 
subserie, la unidad documental, y el componente documental, además de la colección o división de la colección ${ }^{7}$.

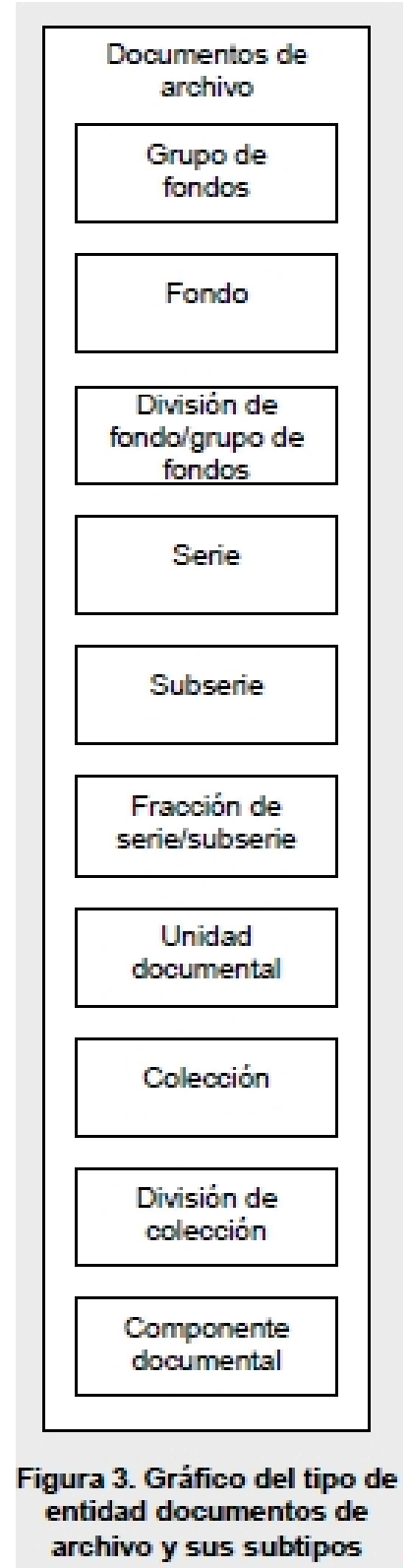

Subtipos del tipo de entidad documentos de Archivo-CNEDA-2011.

${ }^{7}$ Los miembros de la CNEDA en su texto Modelo conceptual..., nota 69 de la p. 31, indican que "En relación con esta cuestión se considera que el nombre de cada uno de los diez subtipos del tipo de entidad documentos de archivo fijados en este documento, puede constituir un valor a incluir en el elemento 3.1.4 de la $\operatorname{ISAD}(G) 2$ (actualmente denominado "nivel de descripción"). Pero esto no significa que la CNEDA considere apropiado el nombre "nivel de descripción" para dicho elemento de la $\operatorname{ISAD}(G) 2$ ". 


\section{MARIANO GARCÍA RUIPÉREZ \\ LA DENOMINACIÓN DE TIPOS, SERIES Y UNIDADES DOCUMENTALES EN ESPAÑA...}

Esta evolución es muy interesante pues implica la desaparición de conceptos muy arraigados utilizados hasta entonces para denominar las agrupaciones documentales, caso de secciones y subsecciones ${ }^{8}$, o la irrupción de otros nuevos con menor o mayor éxito, caso de subfondo o subserie. La CNEDA, en sus últimos trabajos teóricos, ha aportado la unificación, como un único nivel de descripción, de la "unidad documental" sea simple o compuesta ${ }^{9}$, y la posibilidad de describir una parte o un elemento de ésta, utilizando el concepto de "componente documental", ya presente en la NEDA aunque denominado en ella como "elemento de descripción asociado".

Pero el debate no está ni mucho menos cerrado pues en la Norma de descripción archivística de Cataluña (NODAC), publicada en 2007, se distinguen seis niveles de descripción: fondo, subfondo, grupo de series, serie, unidad documental compuesta y unidad documental simple. Los niveles 1 y 2 (fondo y subfondo) corresponden a productores; los niveles 3 y 4 (grupo de series y serie) se refieren a niveles de clasificación de acuerdo con funciones, competencias y actividades; y los niveles 5 y 6 (unidad documental compuesta y unidad documental simple) se destinan a describir documentos individualizados que pueden estar constituidos por más de un documento o por uno solo. Excepcionalmente se puede utilizar, según la $N O D A C$, un séptimo nivel que denominan como "unidad de instalación" 10 .

En Galicia se ha elaborado la Norma galega de descrición arquivística (NOGADA). En su propuesta preliminar, de mayo de 2008, se distinguían seis niveles de descripción: fondo, sección, serie, subserie, fracción de serie y unidad documental $^{11}$. Y así se ha mantenido en su versión en español del año $2010^{12}$.

${ }^{8}$ En la obra colectiva Manual de descripción multinivel: Propuesta de adaptación de las normas internacionales de descripción archivística, publicada en el año 2000 y editada por la Consejería de Educación y Cultura de la Junta de Comunidades de Castilla y León, sus autores, José Luis Bonal Zazo, Juan José Generelo Lanaspa y Carlos Travesí de Diego, distinguían nueve niveles que podían usarse en la descripción: 1. Fondo, 2. Subfondo, 3. Sección, 4. Subsección, 5. Serie, 6. Subserie, 7. Unidad de localización, 8. Documento compuesto, y 9. Documento simple. Véase la p. 23 de ese Manual.

${ }^{9}$ Con esta postura se intenta evitar, en palabras de Javier Barbadillo, "la idea de que una unidad simple siempre debe ser descrita como parte de una compuesta... [pues] una serie puede estar formada por unidades documentales de las dos clases". Véase J. BARBADILLO, Las normas de descripción archivísticas: qué son y cómo se aplican, Gijón, 2011, p. 128.

${ }^{10}$ Norma de descripción archivística de Cataluña (NODAC) 2007, Barcelona, 2007, pp. 2223.

${ }^{11}$ Norma galega de descrición arquivística (NOGADA). Proposta inicial, [S. 1.], [2008], p. 23. Texto en gallego.

${ }^{12}$ Norma gallega de descripción archivística (NOGADA): febrero 2010, [Santiago de Compostela], 2010, pp. 17-18. 


\section{GLOSARIO (NIVELES DE DESCRIPCIÓN)}

Para los efectos de esta norma, los niveles de descripción son los siguientes:

\section{Niveles intelectuales:}

\section{Fondo:}

Conjunto de todos los documentos producidos por un sujeto en el desarrollo de sus actividades o por varios en el ejercicio de una misma función a lo largo del tiempo.

\section{Sección:}

Primera división que responde a la estructura orgánica o funcional del fondo. Las secciones se podrán subdividir en tantos niveles como sea necesario para reflejar la estructura del fondo.

\section{Serie:}

Conjunto de documentos resultantes de una misma actividad producidos por un sujeto productor, o por varios de forma sucesiva a lo largo del tiempo.

\section{Subserie:}

División de la serie en función de la materia, variaciones en el procedimiento, etc.

\section{Niveles físicos:}

\section{Fracción de serie:}

Conjunto de documentos que, formando parte de una serie, se reúnen para su instalación y conservación en una misma unidad fisica.

Unidad documental:

Elemento indivisible de una serie documental que da testimonio de un hecho o acto. Puede ser simple o compuesta.

Niveles de descripción recogidos en la NOGADA-2010.

La inclusión como agrupación documental de las "fracciones de series o subseries" no nos parece oportuna aunque sea muy útil en los estudios de valoración de series y en las transferencias documentales. También existen fracciones de fondo y de divisiones de fondo, e incluso fracciones de unidades documentales ${ }^{13} \mathrm{y}$ no por eso se incluyen como nivel de descripción. En los grandes Archivos estatales es muy normal que las unidades documentales y series que forman un determinado fondo estén conservadas en varios de ellos. Sin ir más lejos para consultar

\footnotetext{
${ }^{13}$ Como tales podemos entender a los "Expedientes incompletos" recogidos como ejemplo de "unidades documentales compuestas" por los redactores de la NEDA del año 2005.
} 


\section{MARIANO GARCÍA RUIPÉREZ \\ LA DENOMINACIÓN DE TIPOS, SERIES Y UNIDADES DOCUMENTALES EN ESPAÑA...}

los documentos generados por algunos de los grandes Consejos territoriales de la monarquía hispánica es preciso acudir al Archivo General de Simancas y al Archivo Histórico Nacional, pues cada uno de ellos conserva una fracción de fondo. Pero no es este el tema que nos ocupa ahora.

Parece claro que en España no conseguimos ponernos de acuerdo ni siquiera en la manera de denominar las agrupaciones documentales ni los niveles de descripción. Pero si nos olvidamos de las colecciones y de los grupos de fondos y nos centramos en las divisiones de un fondo podemos comprobar que las diferencias más claras se centran en la denominación de las agrupaciones de series, bien sea como "divisiones de fondo" (NEDA), bien como "grupos de series" y "subfondos" $(N O D A C)$ o bien como "secciones" (NOGADA). El concepto de "subserie" es totalmente novedoso en España pues apenas se había utilizado antes de la publicación de la versión española de la $\operatorname{ISAD}(G)$ en el año $2000^{14}$. La aparición de cuadros de clasificación que contemplan las subseries y de instrumentos que las describen nos permitirá discernir qué elementos se utilizan en su denominación.

Todos estamos de acuerdo en que la serie es el nivel más importante en la descripción multinivel. Y las series están formadas por unidades documentales que se encuentran en la base de cualquier descripción formando el nivel más inferior, aunque, como hemos visto, en España hay propuestas que consideran las unidades documentales como un único nivel (NEDA y NOGADA), o como dos $(N O D A C)$. En esta última la unidad documental compuesta ocupa un nivel superior al de la unidad documental simple.

\section{TIPO DOCUMENTAL: UN CONCEPTO BÁSICO EN LA DES- CRIPCIÓN DE UNIDADES Y SERIES DOCUMENTALES}

Los archiveros españoles dan una gran importancia en el análisis archivístico al tipo documental pues éste determina la denominación de la serie y sobre ésta, como sabemos, descansan las principales funciones archivísticas (organización, descripción, valoración, difusión...). El papel de la tipología documental en la composición del título de las unidades de descripción es esencial ${ }^{15}$, tanto en las series como en las unidades documentales, así como en los niveles intermedios

\footnotetext{
${ }^{14}$ Curiosamente sí incluyó este concepto J. R. Cruz Mundet en el diccionario básico que recoge en su libro Archivos Municipales de Euskadi: Manual de organización, Vitoria, 1992. En concreto aparece en la p. 207. Recordemos que la primera versión de la Norma $\operatorname{ISAD}(G)$ se publicó en 1994, y en español lo hizo un año después.

15 J. BARBADILLO, Las normas de descripción archivística..., p. 49.
} 


\section{MARIANO GARCÍA RUIPÉREZ \\ LA DENOMINACIÓN DE TIPOS, SERIES Y UNIDADES DOCUMENTALES EN ESPAÑA...}

(subseries y fracciones de serie). En los niveles de descripción superiores a la serie documental la mención de la tipología no es relevante ni oportuna.

La pregunta que nos hacemos ahora es qué entendemos por "tipo documental”, al menos en España, y desde cuándo utilizamos este concepto. Y a su respuesta dedicaremos los siguientes párrafos.

Hace ya unos años, Manuel Vázquez escribió que así como no existen "hombres" en abstracto, sino varones y mujeres, no había "documentos" en abstracto sino tipos documentales ${ }^{16}$. El archivero argentino señaló, también, que aunque era un término usado por los archiveros norteamericanos y de habla hispana, no ocurría así con los franceses, ingleses, italianos o canadienses que se servían de otros conceptos no siempre uniformes ${ }^{17}$. Para él fue adoptado por T. Schellenberg ante la necesidad de clasificar los archivos privados, tomándolo tal vez de un artículo de N. Harlow aparecido en $1955^{18}$. El archivero norteamericano lo utilizaría ampliamente en su libro Técnicas descriptivas de archivos (Córdoba, 1961) indicando que "tipo" era el primer "carácter físico que debe tenerse en cuenta en la descripción de documentos" 19 .

En España, la primera archivera en servirse de este término fue Vicenta Cortés, pues no en vano realizó observaciones al texto citado de T. Schellenberg que se recogieron en su Introducción. Después la siguieron los más prestigiosos archiveros de habla hispana como el ya mencionado Manuel Vázquez, Aurelio Tanodi, Antonia Heredia y Olga Gallego, entre otros. Pero no debemos olvidar que el concepto de tipo documental es una evolución lógica de los de "tipo diplomático" y "tipo jurídico" que han empleado siempre los diplomatistas españoles ${ }^{20}$ y los de otros países en sus análisis documentales. El estudio de los tipos documentales de nuestros días es, pues, una evolución, con enfoques distintos, de los estudios diplomáticos realizados sobre los documentos medievales y modernos.

\footnotetext{
${ }^{16}$ M. VÁZQUEZ, "Reflexiones sobre el término <tipo documental>", en De archivos y de archivistas. Homenaje a Aurelio Tanodi, Washington, 1987, pp. 181-182.

${ }^{17}$ Esto explicaría que el concepto de "tipo documental" no aparezca recogido en el Dictionary of Archival Terminology, ni tampoco en la obra Pratique Archivistique Française, como muy bien comenta Eduardo Núñez Fernández en su Organización y gestión de archivos, Gijón, 1999, p. 101.

${ }^{18}$ M. VÁZQUEZ, "Reflexiones sobre el término <tipo documental>”, p. 178.

19 T. R. SCHELlENBERG, Técnicas descriptivas de archivos, Córdoba, 1961, p. 21. Más adelante al tratar sobre la "descripción de las piezas documentales" expresó como primera regla que "debe indicarse el tipo documental de la pieza" (p. 86).

${ }^{20} \mathrm{M}^{\mathrm{a}}$ S. MARTÍN POSTIGO, La cancillería castellana de los Reyes Católicos, Valladolid, 1959. En el índice del capítulo VI se refiere expresamente al "Estudio diplomático de cada uno de estos tipos documentales". Este libro es un resumen de su tesis doctoral defendida en 1957.
} 
Aún así, está claro que la influencia de las obras de T. Schellenberg motivó que la presencia de la denominación de los tipos en la descripción archivística de las unidades documentales fuera respaldada por la mayoría de las contribuciones teóricas publicadas en España en las últimas décadas del siglo $\mathrm{XX}^{21}$. Pero bastaba con examinar el contenido de los inventarios realizados en los archivos españoles desde la Edad Media para darnos cuenta de que esto era una práctica bastante habitual $^{22}$. La teoría venía así a sancionar lo que llevaba haciéndose en la práctica desde hacía siglos. En los manuales de archivos publicados en España en el siglo XIX el concepto está presente aunque bajo la denominación más habitual de "clase de documentos" 23 . Y tampoco era desconocido para nuestros administrativis$\operatorname{tas}^{24}$.

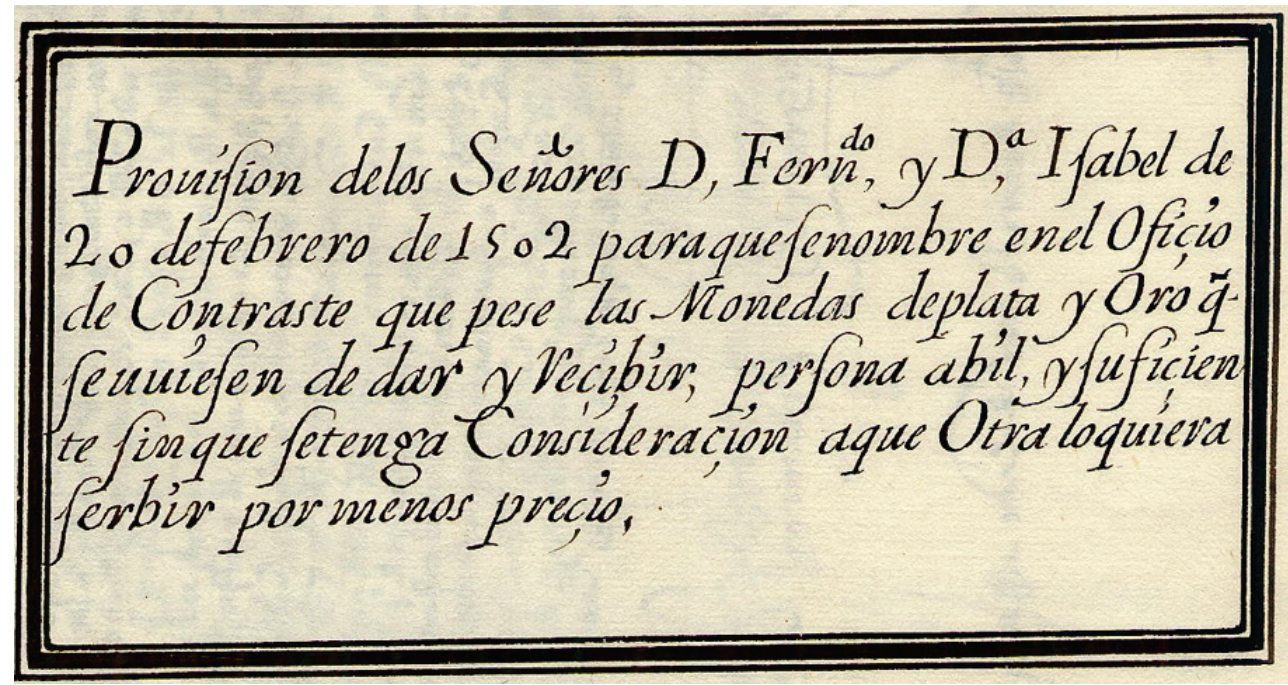

Descripción de un documento del Archivo Municipal de Toledo realizada en el siglo XVII.

${ }^{21}$ En 1987, José Ramón Cruz Mundet publicó un artículo titulado "La catalogación de documentos" en el que exponía la "ficha catalográfica" que había utilizado para describir los documentos medievales de Rentería. En ella distinguía cuatro partes. En la que denomina "Características formales" incluye, junto con las medidas del documento, el idioma, la tradición documental..., la "tipología diplomática", la "tipología jurídica" y la "tipología paleográfica". Véase Bilduma, 1 (1987), pp. 133 y 137.

${ }^{22}$ El término "inventario" era el más utilizado para denominar los instrumentos descriptivos de los archivos en esos siglos. Véase nuestro texto "La descripción de la documentación municipal en España (Siglos XIV-XVIII)", en Los Fondos Históricos de los Archivos Españoles: I Jornadas de Archivos Históricos en Granada, edición en Cd-Rom, [Sevilla], 1999.

${ }^{23}$ Curiosamente T. R. Schellenberg, en la p. 21 de sus Técnicas descriptivas de archivos, había escrito que "el tipo documental puede identificarse al contestar la siguiente pregunta: ¿Qué clase de documento es éste?".

${ }^{24}$ En la Ley de Procedimiento Administrativo, aprobada en España en 1958, se incluye, en su artículo 30.1, lo siguiente: "Los documentos y expedientes administrativos serán objeto de normalización para que cada serie o tipo de los mismos obedezca a iguales características y formato". Véase $B O E$, núm. 171, de 18 de julio de 1958, p. 1280. 


\section{MARIANO GARCÍA RUIPÉREZ \\ LA DENOMINACIÓN DE TIPOS, SERIES Y UNIDADES DOCUMENTALES EN ESPAÑA..}

Sin duda las publicaciones de T. Schellenberg potenciaron la difusión del concepto de "tipo documental", que revelaba, según él, tanto el contenido como la estructura física del documento ${ }^{25}$ aunque el archivero norteamericano lo incluyó entre los caracteres externos o físicos junto con la clase, el formato, la forma y la cantidad.

Si la obra Técnicas descriptivas de archivos $^{26}$ inició el camino de la normalización de la descripción en España ${ }^{27}$, los trabajos de A. Heredia Herrera, publicados en la década de 1980, sentaron las bases para la descripción documental ${ }^{28}$. La archivera sevillana es la que más atención ha prestado, y presta, en nuestro ámbito a esta temática. Ahora bien, la importancia del tipo documental en el quehacer archivístico había sido resaltada, también, por Vicenta Cortes Alonso ${ }^{29}$ al afirmar que "la determinación del tipo... [permitiría] saber de qué documento se trata y cuáles son sus iguales, para ponerlos juntos y ordenarlos en series" ${ }^{30}$. Exponía que el análisis documental serviría para conocer adecuadamente la "denominación y definición de los documentos". Es más, Vicenta Cortés nos aportó la primera definición que conocemos realizada en España sobre "tipo documental" desde el campo de la archivística. Y lo hizo ya en 1982. En concreto, para la que fuera Inspectora General de Archivos, el "tipo del documento es el número y disposición de los elementos de la información que corresponden a la actividad que lo ha producido" 31 .

Los archiveros municipales madrileños definen "tipo documental" como la “expresión de las diferentes actuaciones de la Administración reflejadas en un

${ }^{25}$ T. R. SCHELLENBERG, Técnicas descriptivas de archivos, p. 26.

${ }^{26}$ Este libro fue repartido por el propio T. R. Schellenberg entre los asistentes a la "Primera Reunión Interamericana sobre Archivos (PRIA)", celebrada en Washington D.C., del 9 al 27 de octubre de 1961, al que asistieron 49 profesionales de América y de España. Esta reunión está considerada como la base para el actual desarrollo de la Archivística en Iberoamérica.

27 A. HEREDIA HERRERA, "El nuevo modelo de descripción archivística", en Memoria XXII Congreso Archivístico Nacional: "Los pilares de la Archivística. Clasificación, ordenación y descripción, San José (Costa Rica), 2011, p. 109.

${ }^{28}$ Nos referimos en concreto a: "Los instrumentos de descripción”, en Archivística: estudios básicos, Sevilla, 1981, pp. 73-86; Manual de instrumentos de descripción documental, Sevilla, 1982; y Archivística general: teoría y práctica, Sevilla, 1986. En el libro colectivo Archivística: estudios básicos se incluyen tres trabajos realizados por una diplomatista y un archivero cuyos títulos se inician con las palabras "Tipología documental".

${ }^{29}$ El primer texto que conocemos de Vicenta Cortés relativo a la importancia del tipo documental en la organización de los documentos es su artículo "Los documentos y su tratamiento archivístico" aparecido en el Boletín de ANABAD, XXXI: 3 (1981), pp. 365-381.

${ }^{30} \mathrm{~V}$. CORTÉS ALONSO, "Nuestro modelo de análisis documental", Boletín de ANABAD, XXXVI: 3 (1986), p. 420.

${ }^{31}$ V. CORTÉS ALONSO, Manual de archivos municipales, Madrid, 1982, p. 47. De los "tipos documentales" trata también en las pp. 58-60. 


\section{MARIANO GARCÍA RUIPÉREZ \\ LA DENOMINACIÓN DE TIPOS, SERIES Y UNIDADES DOCUMENTALES EN ESPAÑA...}

determinado soporte y con unos mismos caracteres internos específicos para cada uno, que determinan su contenido"32. En el Diccionario de terminología archivística, publicado por el Ministerio de Cultura español en 1993, se recoge como la "unidad documental producida por un organismo en el desarrollo de una competencia concreta, regulada por una norma de procedimiento y cuyo formato, contenido informativo y soporte son homogéneos" 33 . Estas dos definiciones crean confusión. La primera al identificar "tipo" con "expresión” toda vez que por entonces se había publicado en la Ley 16/1985 de Patrimonio Histórico Español, y en concreto en su art. 49, una definición de documento que lo identificaba con "toda expresión en lenguaje natural o convencional...”. Un tipo documental no es un documento y por lo tanto tampoco una "unidad documental". Y no podemos limitar "tipo" al ámbito exclusivo de la administración pública.

Unos años después, la Mesa de Trabajo de Organización de Archivos Municipales definió "tipo documental" como el "término o expresión que condensa las características tanto de origen como formales e informativas de una unidad documental distinta de otra" 34 . Estaba claro que ya no se identificaba "tipo" con "unidad documental" 35 , al menos para los archiveros que integran la Mesa. El glosario de términos publicado en la versión española de la Norma $\operatorname{ISAD}(G)$ del año 2000 no ayudó mucho pues definió "tipo documental" como "clase de documentos que se distingue por la semejanza de sus características físicas (por ejemplo, acuarelas, dibujos) y/o intelectuales (por ejemplo, diarios, dietarios, libros de actas)"36.

32 Grupo de Archiveros Municipales de Madrid, Manual de tipología documental de los municipios, Madrid, 1988, pp. 12 y 179.

${ }^{33}$ Diccionario de terminología archivística, Madrid, 1993, p. 52.

${ }^{34}$ Mesa de Trabajo sobre Organización de Archivos Municipales, Archivos municipales: Propuesta de cuadro de clasificación de fondos de ayuntamientos, Madrid, 1996, p. 15. Por entonces A. Heredia redactó su propia definición de tipo bastante similar. En concreto afirmaba que "tipo documental es el término o expresión que sirve para condensar y globalizar las características esenciales tanto formales como informativas de una unidad documental". Véase A. HEREDIA HERRERA, La Norma ISAD $(G)$ y su terminología. Análisis y alternativas, Madrid, 1995, p. 61.

${ }^{35}$ En la versión española de la Norma internacional general de descripción archivística $\operatorname{ISAD}(G)$, publicada en 1995 por el Ministerio de Cultura, en la nota 7 de la p. 15, figura que "tipología o tipo documental... se define como la unidad documental generada, reunida y conservada por un sujeto productor...”.

${ }^{36} \operatorname{ISAD}(G)$ : Norma internacional general de descripción archivística..., versión española de Asunción de Navascués Benlloch..., 2 $2^{\mathrm{a}}$ ed., Madrid, 2000, p. 18. Recordemos que en la publicación oficial del CIA de esta Norma, realizada en Ottawa, en el año 2000, en el glosario de términos recogido en ella, en su p. 11, aparece "Form" que fue traducido en la versión española por "Tipo documental". La definición de "Form" es la siguiente: "A class of documents distinguished on the basis of common physical (e.g., water colour, drawing) and/or intellectual (e.g., diary, journal, day book, minute book) characteristics of a document". La definición dada en la versión española del año 2000, sin apenas variaciones, será copiada en otras obras posteriores y por otros autores, de 


\section{MARIANO GARCÍA RUIPÉREZ \\ LA DENOMINACIÓN DE TIPOS, SERIES Y UNIDADES DOCUMENTALES EN ESPAÑA...}

Constatamos así como, poco a poco, han ido ganando terreno los que entienden el tipo documental como un modelo que permite reconocer a las unidades documentales semejantes. El tipo documental es "indispensable a la hora de reconocer y representar cualquier unidad documental [y] su denominación ayuda no solo a fijar el nombre de cada unidad documental sino el de la serie". Así lo expresó A. Heredia en un estudio publicado en el año $2006^{37}$. En él realiza un repaso sobre las principales aportaciones teóricas sobre este concepto, incluyendo algunas procedentes de Iberoamérica. Entre ellas es de resaltar la expresada por M. Vázquez que identificó "tipo documental” con "el carácter o atributo (de un documento de archivo), que: se origina en la función y actividad administrativa para la que nació el documento; se manifiesta en una diagramación, formato y contenido distintivos; sirve para ordenarlo, describirlo y, en general, procesarlo" 38 .

La idea de tipo documental como modelo fue difundida en otros trabajos impresos coetáneos al mencionado de Antonia Heredia ${ }^{39}$, pero será ella la que de nuevo lo aclare en su Lenguaje y vocabulario archivísticos. Algo más que un diccionario. En esta obra nos da dos definiciones. Tipo documental es "la forma de manifestarse la información" y también "la estructura y disposición de los elementos de la información en un documento de archivo" 40 . Esta última tiene una clara relación con la dada por Vicenta Cortés en 1982.

forma idéntica o con modificaciones. Así, por ejemplo, en la p. 189 de la NODAC (2007) se prefiere la denominación de "Tipología" entendida como "Tipo de documentos que se distinguen por las características físicas (por ejemplo, acuarela, dibujo) y/o intelectuales (por ejemplo, diario, dietario, libro de notas) comunes". Como vemos la palabra "minute book" traducida en la versión española por "libro de actas" es identificada ahora por los redactores de la NODAC como "libro de notas". En ninguna de las dos se traduce el término "journal", posiblemente "revista". Y "diary" puede ser un "periódico". Por otro lado, debemos indicar que la "acuarela", entendida como una "pintura sobre papel o cartón con colores diluidos en agua" no es nada corriente que se conserve en un archivo, por lo que este ejemplo, como buena parte de los elegidos, son poco representativos y crean confusión.

37 A. HEREDIA HERRERA, "En torno al tipo documental", Boletín de ANABAD, LVI: 3 (2006), p. 32.

${ }^{38}$ M. VÁZQUEZ, Administración de documentos y archivos: planteos para el siglo XXI, $2^{\mathrm{a}}$ edición, Buenos Aires, 2006, p. 31. Esta definición la había incluido ya, con muy pocos cambios, en la p. 181 de su artículo "Reflexiones sobre el término...", publicado en 1987.

${ }^{39}$ Véase el ya citado de Javier Barbadillo Alonso titulado "Apuntes de clasificación archivística". En él indica, en su p. 37, que "un tipo es una abstracción, no es una cosa ni un grupo de cosas, sino un conjunto de criterios". Por nuestra parte, en nuestro estudio Tipología, series documentales, cuadros de clasificación: cuestiones metodológicas y prácticas (Las Palmas de Gran Canaria, 2007, pp. 35-36), afirmamos que "el tipo documental no deja de ser un modelo teórico que al vincularlo a un productor y a una actividad concreta, y repetirse en el tiempo, formaría la serie, susceptible de ser identificada, clasificada, valorada y descrita".

${ }^{40}$ A. HEREDIA HERRERA, Lenguaje y vocabulario archivisticos..., p. 176. 


\section{MARIANO GARCÍA RUIPÉREZ \\ LA DENOMINACIÓN DE TIPOS, SERIES Y UNIDADES DOCUMENTALES EN ESPAÑA...}

Lo interesante de la aportación de Antonia Heredia son sus reflexiones. Al comentar este concepto destaca que no hay tipos documentales simples o compuestos ya que lo que sí existen son unidades documentales. Para ella es una característica de los documentos, que unos han considerado interna y otros externa. El tipo documental es expresión de formalidades y de contenido a partir del procedimiento. Refleja una superposición de la tipología diplomática y de la tipología jurídica y, por ende, administrativa. Además, en su texto, aporta ejemplos de tipos documentales, tales como la Real cédula, el testamento, el padrón de habitantes, el inventario de bienes, la carta, la carta de dote, el expediente de declaración de ruina y el expediente de licencia de obra menor.

Por su parte, J. R. Cruz Mundet se ha limitado, en su Diccionario de Archivística ${ }^{41}$, a incluir, sin comentar, la definición de "tipo documental" publicada por Ana Duplá del Moral $^{42}$ hacía ya unos años. La que fue directora del Archivo Regional de la Comunidad de Madrid entiende "tipo documental" como la "expresión tipificada de unidades documentales con unas características estructurales, en general, homogéneas, de actuaciones únicas o secuenciales, normalmente reguladas por una norma de procedimiento, derivadas del ejercicio de una misma función y realizadas por un determinado órgano, unidad o persona con competencia para ello"43. La explicación de este concepto lo realizó su autora en la introducción de su Manual de archivos de oficina... Exponía Ana Duplá que su mención a unas "características estructurales, en general homogéneas" es más ajustada que la de "unos mismos caracteres internos (o externos) que se emplean en otras definiciones, pues en un mismo tipo el contenido testimonial e informativo no es homogéneo, ni la clase ni el soporte tienen que serlo". La referencia a "actuaciones únicas o secuenciales" alude a las unidades documentales simples o compuestas, resultado de esas actuaciones. Reconoce que existen tipos propios de instituciones privadas que no están regulados por el procedimiento administrativo y de ahí la frase "normalmente reguladas por una norma de procedimiento", pretendiendo así que sirva también para los primeros. Cree, además, que el ejercicio de una misma

${ }^{41}$ J. R. CRUZ MUNDET, Diccionario de Archivística, Madrid, 2011, p. 342. Curiosamente es un término por el que nuestro compañero no ha prestado apenas atención en sus publicaciones, siempre interesantes. Por ejemplo, no se recoge en el "Diccionario básico" que incluye en su libro Archivos municipales de Euskadi: manual de organización, Vitoria, 1992. Y tampoco aparece en el glosario recogido como apéndice en la obra colectiva Manual de descripción multinivel... ya citada.

42 A. DUPLÁ DEL MORAL, "Glosario de terminología archivística”, Revista del Archivo General de la Nación (Perú), 25 (2005), p. 47.

${ }^{43}$ Ana Duplá del Moral ya aportó esta definición en su Manual de archivos de oficina para gestores: Comunidad de Madrid, Madrid, 1997, p. 84. 


\section{MARIANO GARCÍA RUIPÉREZ \\ LA DENOMINACIÓN DE TIPOS, SERIES Y UNIDADES DOCUMENTALES EN ESPAÑA...}

función es el elemento más importante para la configuración de cada tipo documental, aunque lo más adecuado habría sido indicar "una misma actividad". Y concluye expresando que "la suma de las unidades documentales que pertenecen a un mismo tipo documental y el órgano o unidad que ha producido los documentos que a él pertenecen es lo que conformará la serie documental" 44 .

Por último, los miembros de la CNEDA, en el año 2011, se han decantado por una definición más comprensible y actualizada que la recogida en la versión española de la Norma $\operatorname{ISAD}(G)$ del año 2000. Así han definido "Tipo documental" como el "Modelo de unidad documental que se distingue por tener unas características físicas o intelectuales comunes" ${ }^{4}$. Es decir, han introducido el concepto de "modelo", que es esencial para entender la idea de tipo documental, y han suprimido los ejemplos para evitar confusión. Además han prescindido de la posibilidad de que las unidades documentales de un mismo tipo puedan tener características físicas e intelectuales comunes al apostar por el uso de "o" y no del "y/o". Pero puede que lo más razonable hubiera sido sustituir la conjunción disyuntiva "o" por la conjunción copulativa " $y$ ".

Es decir, estamos ante un modelo que nos permite agrupar unidades documentales con características semejantes. Esas similitudes están relacionadas con la información que contienen y con la manera de distribuir esa información en el soporte elegido. Es lo que otros compañeros han identificado con "diagramación", "estructura" o "disposición", condicionada a veces también por el formato y el soporte documental. Pero lo que en realidad identifica a los tipos documentales es su finalidad, es decir el motivo de su realización, su objeto. Su estructura puede cambiar con el tiempo pero si se mantiene su finalidad es muy posible que se mantenga también su denominación. La doctora Vicenta Cortés indicó que el nombre del tipo se deriva de esa actividad, como por ejemplo "informe" procede de la acción de "informar". Más de cien años antes otro archivero había escrito que "la esencia de todo documento, su unidad lógica o inmaterial, lo que absolutamente le determina y por lo que es lo que es, sin que se confunda con otro, es: $s u$ hecho (factum), su objeto $^{46}$, que es un concepto o pensamiento siempre contenido en una proposición principal absoluta de su contexto, expresa o sobreentendida, v.

\footnotetext{
${ }^{44}$ A. DUPLÁ DEL MORAL, Manual de archivos de oficina..., pp. 34-35.

45 Comisión de Normas Españolas de Descripción Archivística (CNEDA), Modelo conceptual de descripción archivística y requisitos de datos básicos de las descripciones de documentos de archivo, agentes y funciones, [Sevilla], 2011, p. 17 y nota 49 de la p. 28.

${ }^{46}$ Recordemos que por "finalidad" debemos entender el "objeto o motivo con que se ejecuta algo", tal y como figura en el Diccionario de la Real Academia Española.
} 


\section{MARIANO GARCÍA RUIPÉREZ \\ LA DENOMINACIÓN DE TIPOS, SERIES Y UNIDADES DOCUMENTALES EN ESPAÑA...}

gr.: Juan vende a Pedro (escritura o contrato de compraventa de Juan a Pedro); el Rey prohíbe el duelo (ley o decreto Real contra el desafío)..."47.

\section{EL TIPO DOCUMENTAL EN LAS DESCRIPCIONES ANTERIO-} RES A LA ISAD(G)

A estas alturas de nuestra exposición parece claro que, al menos en España, un "tipo documental" es un modelo en el que puede manifestarse la información. Entrar en el debate de si tiene la consideración de carácter externo, interno o mixto ahora no tiene sentido, pero dada su incidencia en la denominación de las unidades documentales y series tal vez sea oportuno recordar algunas posturas no coincidentes defendidas en España antes de la difusión de la Norma $\operatorname{ISAD}(G)$. Y lo haremos deteniéndonos en los dos autores que más han influido en la teoría archivística española en las últimas décadas.

José Ramón Cruz Mundet, en 1987, en una de sus aportaciones teóricas más tempranas, abogó por la mención del tipo diplomático entre los caracteres externos como un elemento auxiliar y cuya cita no era esencial en la descripción catalográfica ${ }^{48}$. Expresaba que la utilización de la tipología diplomática en la catalogación de documentos se consideraba poco acertada por la inexistencia de estudios diplomáticos sobre ellos, salvo para los medievales y los emanados de la cancillería pontificia. La estructura de los documentos no permitía "en todos los casos dirimir a ciencia cierta su tipología diplomática" y "pocos son los investigadores que encuentran en esta tipología un elemento valioso para su consulta". Este argumento había sido utilizado, por entonces, por Carmela Pescador del Hoyo en su libro El Archivo: instrumentos de trabajo ${ }^{49}$. La reconocida archivera indicaba en esa obra que "por ser a veces difícil de determinar son muchas las publicaciones en las que no figura [el tipo diplomático] por ninguna parte en la ficha". Para ella era un "dato de interés secundario" y accesorio que incluso no era preciso consignar ni siquiera entre los elementos externos ${ }^{50}$. José R. Cruz Mundet ha seguido

\footnotetext{
${ }^{47}$ J. MORÓN Y LIMINIANA, Metodología diplomática o manual de Arquivonomía: tratado teórico-práctico del orden que debe observarse en los archivos para su arreglo, conservación y servicio..., Valencia, 1879, p. 191.

48 J. R. CRUZ MUNDET, “La catalogación de documentos”, Bilduma, 1 (1987), p. 137.

${ }^{49}$ C. PESCADOR DEL HOYO, El Archivo: instrumentos de trabajo, Madrid, 1986, p. 153. Esta postura la había defendido en otros trabajos anteriores. Véase su texto "El problema de la descripción de fondos documentales", publicado en De archivos y archivistas..., pp. 123-124.

${ }^{50}$ Carmela Pescador escribía, en la nota 8 de esa p. 153, que "Todo el mundo sabe, más o menos, lo que es un privilegio, una real orden, una carta de venta o un testamento, pero si no conocemos los tipos diplomáticos de los demás documentos que tenemos que reseñar más nos vale
} 


\section{MARIANO GARCÍA RUIPÉREZ \\ LA DENOMINACIÓN DE TIPOS, SERIES Y UNIDADES DOCUMENTALES EN ESPAÑA...}

defendiendo esta postura, ya iniciado el siglo XXI, incluso después de publicarse la versión española de la Norma $\operatorname{ISAD}(G)$, pues entendía que al describir un documento "comenzar por el tipo diplomático (Real Cédula, Decreto...) carece de rigor científico, pues se trata de un elemento secundario" $"$.

Bien diferente es la postura que ha mantenido siempre Antonia Heredia. En 1981 escribió que la tipología documental (diplomática y jurídica) era un elemento indispensable en la catalogación de los documentos, pues los archiveros "con la indicación expresa de ambas habremos fijado la mayor parte de los datos que delimitan al documento" 52 . Por ello incluyó la mención de la tipología entre los datos internos, junto con el autor, el destinatario y el asunto. Y este punto de vista, desarrollado, lo ha defendido en otras obras posteriores, especialmente en su $\mathrm{Ar}$ chivística general: teoría y práctica, cuya primera edición apareció en 1986. En este manual, la archivera sevillana exponía que la designación del "tipo documental" era necesaria 53 , y a la hora de describir "hemos de inclinarnos por... [la tipología diplomática] no dejando de expresar también la jurídica"54. En posteriores ediciones de su Archivística general, como la aparecida en 1991, ya expresó que la tipología documental abarcaba tanto los documentos singulares como las unidades archivísticas, es decir lo que ahora denominamos unidades documentales simples y compuestas. Su especificación era el resultado "de un estudio a fondo del documento, de su génesis, de su tramitación, incluso de su formato que nos lleva de la mano a su contenido solo con su denominación, por cuanto la disposi-

no poner nada como tal dato descriptivo, dando la impresión de falta de conocimiento e irregularidad". Su libro tiene un antecedente claro en el texto de Carmen Crespo Nogueira, "Terminología de archivos", publicado en el Homenaje a Federico Navarro (Madrid, 1973). En su p. 94, la que fue directora del Archivo Histórico Nacional, había manifestado que al describir "un documento medieval llevará indicaciones de tipo de letra, dimensiones, categoría diplomática, etc., que no son aplicables a documentos más recientes".

${ }^{51}$ J. R. CRUZ MUNDET, Manual de Archivística, 5a ed., Madrid, 2003, p. 291. En esta obra sigue defendiendo la mención de la tipología diplomática entre las "características físicas". La inclusión entre ellas de la "Tipología diplomática" debía hacerse "siempre que pueda establecerse con acierto y teniendo la precaución de no aceptar a pie juntillas la autocalificación que al respecto puede llevar el documento, sin antes haberla contrastado con el estudio de su estructura". En Ídem, p. 292.

52 A. HEREDIA HERRERA, "Los instrumentos de descripción”, en Archivística: estudios básicos, Sevilla, 1981, p. 92. Este texto era un resumen del libro que publicaría un año después titulado Manual de instrumentos de descripción documental, en la misma ciudad y por el mismo editor.

${ }^{53}$ Esa misma idea la había expresado T. R. Schellenberg en sus Técnicas..., p. 21, al expresar que "el primer requisito para describir un documento es el de indicar su tipo, y esto es cierto respecto a los documentos de cualquiera época".

${ }^{54}$ A. HEREDIA HERRERA, Archivística general: teoría y práctica, 2a ed., Sevilla, 1987, p. 278. 


\section{MARIANO GARCÍA RUIPÉREZ \\ LA DENOMINACIÓN DE TIPOS, SERIES Y UNIDADES DOCUMENTALES EN ESPAÑA...}

ción de todos estos considerandos son el testimonio de una actividad específica que facilita una información determinada". Y continúa señalando que "la designación del tipo documental ha de basarse en la fijación terminológica determinada por los estudios realizados por los diplomatistas o por la legislación que ha establecido sus características y no por la denominación equivocada, en algunos, de la época" 55 .

La línea que hemos trazado basándonos en las aportaciones teóricas de Carmen Crespo, Carmela Pescador y José Ramón Cruz Mundet ha tenido sus defensores pero es minoritaria ${ }^{56}$. La mayoría de los catálogos documentales editados en España en la década de 1980, y en la siguiente, adoptaron el criterio de iniciar la descripción de los datos o caracteres internos con la tipología, tuviera la consideración para sus autores de carácter externo, interno o mixto. Sus referentes teóricos más importantes han sido las obras de Vicenta Cortés ${ }^{57}$, Olga Gallego y Pedro López ${ }^{58}$ y por supuesto Antonia Heredia. Y lo que hacen estos autores es reflejar en sus textos la tradición archivística española pues así se había venido haciendo desde la Edad Media aunque no de una forma homogénea, porque si algo caracteriza a los instrumentos descriptivos elaborados en España durante el Antiguo Régimen es su falta de uniformidad. Aún así, en ellos, la mención de la tipología diplomática y/o jurídica es un elemento bastante frecuente en las descripciones documentales.

Si echamos una mirada a los primeros textos impresos sobre Archivística en España, ya en el siglo XIX, comprenderemos mejor esta argumentación. Froilán Troche y Zúñiga, en su libro El archivo cronológico-topográfico. Arte de archiveros... ${ }^{59}$, escrito en $1830^{60}$, al referirse al "arte de extractar" indicaba que un extrac-

\footnotetext{
${ }^{55}$ A. HEREDIA HERRERA, Archivística general: teoría y práctica, $5^{\mathrm{a}}$ ed., Sevilla, 1991, pp. 364-365.

${ }^{56}$ Así lo expuso Cayetano Tornel Cobacho en Las fichas de catálogo de documentos textuales de archivo..., Cartagena, 1990, p. 19. Este autor también prefería incluir la tipología en el área que denomina "Descripción externa e información adicional",

${ }^{57}$ V. CORTÉS ALONSO, Manual de archivos municipales, p. 96.

${ }^{58}$ O. GALLEGO DOMÍNGUEZ y P. LÓPEZ GÓMEZ, Introducción a la Archivística, Vito-
} ria, 1988, p. 100.

${ }^{59}$ Existe una edición facsimilar de esta publicación debida a Rodrigo Fernández Carrión y a Antonio Sánchez González, encargados de su edición y estudio crítico, publicada en Sevilla, por Padilla ediciones, en 1996.

${ }^{60}$ La primera edición de este libro apareció en 1828, en Santiago, Imprenta de Pascual de Arza, con bastantes menos páginas. Su segunda edición fue publicada en 1835, en la imprenta coruñesa de Iguereta. El título completo es el siguiente: El archivo cronológico-topográfico. Arte de archiveros: método facil, sencillo y poco costoso para el arreglo de los archivos particulares, útil a los hacendados y poseedores de bienes que tienen documentos para conservar sus intereses: arreglo interior y económico de las casas dirección y manejo de los intereses de ellas. Sobre su 
to debía comprender "la clase de documento según el verdadero nombre que deba aplicársele, los sugetos por quien haya sido otorgado, o jueces que hayan hecho oficio de actores, la cosa o suceso sobre que lo hicieron en bosquejo, el lugar y día de su fecha, y el escribano o sugeto que lo haya autorizado"61. En un texto impreso anterior de otro archivero, Facundo Porras Huidobro, al referirse a la Diplomática expresó que "da su nombre propio a toda clase de escritos,..., poniéndoles en la categoría que les es propia... Por medio de sus caracteres intrínsecos y extrínsecos busca legalmente la legitimidad o falsedad que ellos encierran..."62.

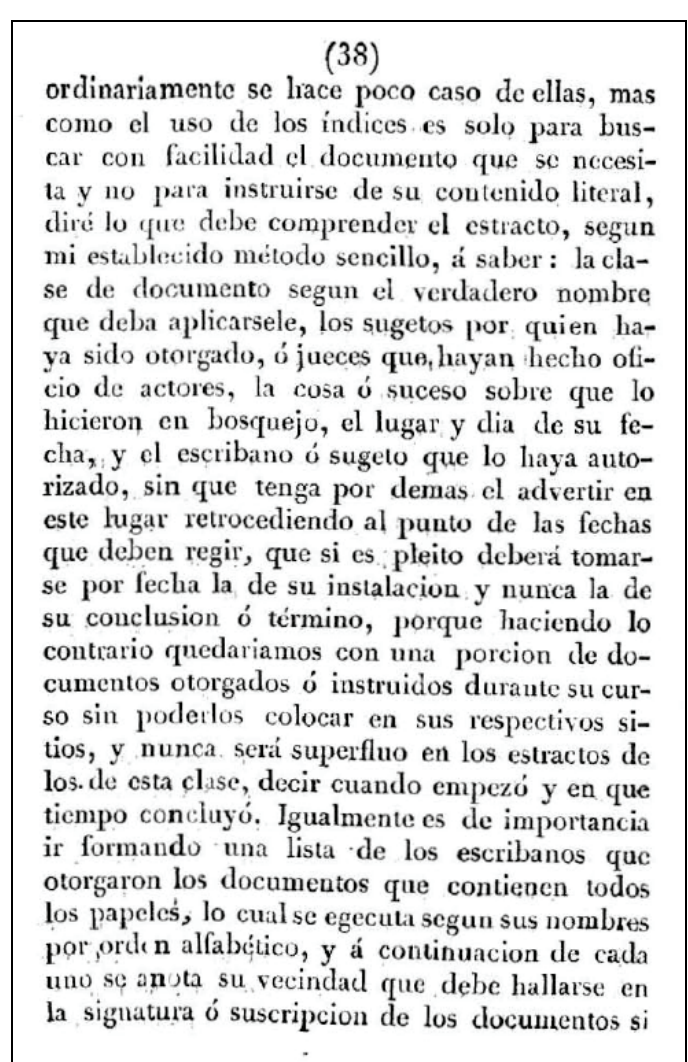

F. Troche y Zúñiga explica en qué consiste el arte de extractar, 1835.

autor puede leerse el artículo de Vítor Manuel Migués Rodríguez, “A fidalguía galega a comienzos do S. XIX: a obra de Froylán Troche y Zúñiga”, Anuario Brigantino, 18 (1995), pp. 117-128.

${ }^{61}$ F. TROCHE Y ZÚÑIGA, El archivo cronológico-topográfico..., 2 ${ }^{\mathrm{a}}$ ed., p. 38 . En la p. 73 de este libro señala que a la hora de elaborar los índices, lo que hoy entenderíamos por catálogos, no debíamos recoger "escritura de foro, de arriendo, de dote, etc." sino "foro, venta, dote, etc. porque escrituras ya sabemos que lo son sin que lo escribamos".

${ }^{62}$ F. PORRAS HUIDOBRO, Discurso diploma-paleográfico que en el ejercicio de oposición a la plaza de archivero de la M. H. Villa y Corte de Madrid pronunció..., Burgos, 1821, p. 13. No obstante al referirse en la p. 19 al "extracto" del documento, este autor no menciona la "clase" o tipo documental. Estas ideas las desarrolló más por extenso en su libro Disertación sobre archivos y reglas de su coordinación..., Madrid, 1830. Con él mantuvo una polémica interesante al enjuiciar la obra de F. Troche y Zuñiga. Este último le contestó en su segunda edición aparecida en 1835. 
Décadas después, en 1879, otro archivero tratadista llamado José Morón y Liminiana, escribía que al redactar la papeleta que describía el documento "se empieza por designar la clase del documento, y para estampar un nombre inicial: Donación Real, Venta, Laudo, Sentencia, Apoca, Testamento, o cualquiera otro, es preciso nada menos que ver casi todo el documento... Estos nombres iniciales determinantes, escritos con carácter abultado, sirven luego para la clasificación, o mas bien, distribución y agrupación de las papeletas por clases" ${ }^{63}$. Más adelante señaló, en esa misma publicación, que "las formas intrínsecas y sus respectivos formularios, son, tal vez, el primer elemento de sólida y segura clasificación. La dificultad podrá estar en saberlas, conocerlas, buscarlas, encontrarlas y distinguirlas: esta es la primera obligación del archivero" ${ }^{4}$.

En este interesante manual, su autor incluyó un modelo de papeleta de "extracto" en el que además de recoger los datos de clasificación y signatura, iniciaba la descripción con la clase del documento, y seguía recogiendo, utilizando sus propios términos, la persona expediente, la personalidad a que se expide, el extracto del contexto del documento, la fecha completa y las observaciones ${ }^{65}$. Además incluyó un modelo cumplimentado en el que figura la palabra "privilegio" en el apartado de "clase del documento".

Modelo de papeleta de extracto impresa, que tambien puede servir para manuscrito.

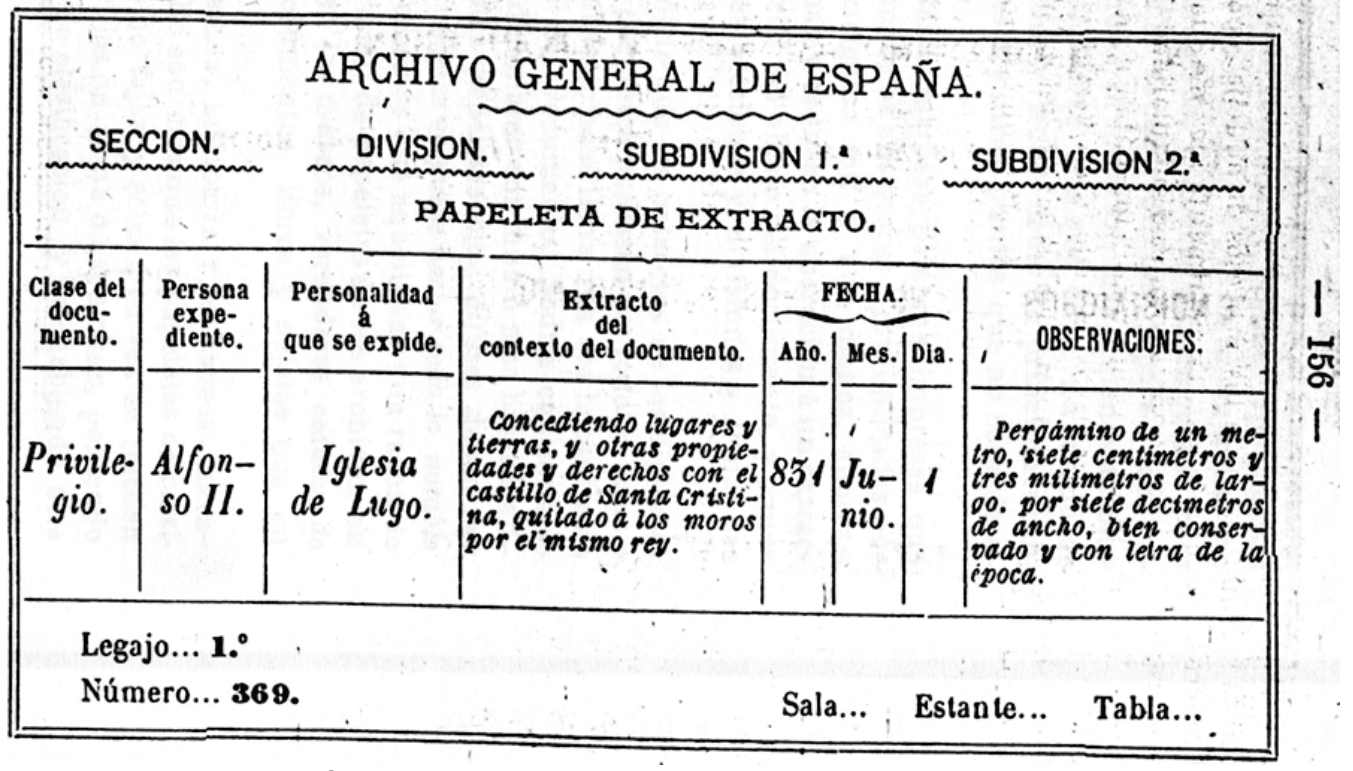

J. MORÓN Y LIMINIANA, Manual de Arquivonomía, 1879, p. 156.

${ }^{63}$ J. MORÓN Y LIMINIANA, Metodología diplomática o manual de Arquivonomía, p. 131.

${ }^{64}$ J. MORÓN Y LIMINIANA, Metodología diplomática..., p. 184.

65 ídem, p. 156. 


\section{MARIANO GARCÍA RUIPÉREZ \\ LA DENOMINACIÓN DE TIPOS, SERIES Y UNIDADES DOCUMENTALES EN ESPAÑA...}

Podríamos recoger otras aportaciones similares de la época, o posteriores, pero lo consideramos innecesario para nuestra argumentación. Lo evidente es que, al iniciarse el siglo XXI, en España había dos claras corrientes o escuelas en la descripción a nivel de unidad documental y en lo relativo al tema que nos ocupa. Para unos la presencia del tipo documental en el área de los caracteres internos era fundamental, junto con el autor, el destinatario y el asunto o contenido, tal y como se venía haciendo en España desde hacía siglos. Para otros, si se recogía, debía contemplarse entre los caracteres externos, y como algo accesorio, no obligatorio. La cuestión no es baladí. La Norma $\operatorname{ISAD}(G)$ al configurar el contenido del elemento "Título" apoyará la primera postura.

\section{EL TIPO DOCUMENTAL EN LAS ACTUALES NORMAS DE DESCRIPCIÓN ESPAÑOLAS}

Recordemos que la $\operatorname{ISAD}(G)$, en su versión española del año 2000, incluyó en su glosario una definición de tipo documental, basándose en la traducción del término "Form" que aparece en la versión de la Norma en inglés, como ya hemos comentado. Los ejemplos incluidos en esa definición de tipo documental no son muy acertados para aclarar el concepto, pero figuran en la versión inglesa de la que la española es una adaptación. Al menos, en la traducción española, se recogen los de "diarios, dietarios y libros de actas" que sí podemos considerar tipos de documentos de archivo. Pero de esa definición nos debemos quedar fundamentalmente con la idea de que lo que distingue a un tipo son sus características físicas y/o intelectuales. Sobre ello trataremos más adelante.

Tipo documental. Clase de documentos que se distingue por la semejanza de sus características físicas (por ejemplo, acuarelas, dibujos) y/o intelectuales (por ejemplo, diarios, dietarios, libros de actas). (Form)

Título. Palabra, frase, carácter o grupo de caracteres que sirve para denominar la unidad de descripción. (Tisle)

Título atribuido. Título atribuido por el archivero a la unidad de descripción que carece de título formal. (Supplied title)

Título formal. Título que figura en un lugar preferente en la documentación que se describe. (Formal title)

Definiciones incluidas en el glosario de la $\operatorname{ISAD}(G), 2000$.

Como sabemos, en la $\operatorname{ISAD}(G)$ el elemento "Título" se incluye dentro del “Área de identificación”. Su objetivo es “denominar la unidad de descripción”. En 
la Norma, tras mostrar preferencia por el "título formal", se indica que "en los niveles inferiores ${ }^{66}$ puede incluirse, por ejemplo, el nombre del autor del documento así como un término que indique el tipo documental de los documentos de la unidad de descripción y, en su caso, alguna expresión que refleje la función, la actividad, el objeto, la ubicación, o el tema"67. Los ejemplos de descripción recogidos en ella no son muy clarificadores.

También en el año 2000 se publicó en España el Manual de descripción multinivel... en el que se distinguían tres tipos de títulos, el transcrito del original (título formal), el redactado por el archivero (título atribuido) y el extraído de una fuente oficial (título oficial). Este último se definía como el "título que se asigna a las unidades de descripción de los niveles intelectuales que se extrae de la normativa de creación, organización o funcionamiento del organismo productor" ${ }^{68}$. Pero para los autores de este manual los niveles intelectuales abarcaban desde el fondo a la subserie. Para nosotros no cabe duda de que el "título oficial" nos será esencial, también, para definir y denominar los tipos presentes en las unidades documentales que forman los niveles inferiores, especialmente en las de origen público.

La $N E D A$, aprobada cinco años después en su primera versión, y hasta ahora única, y refiriéndose especialmente a la unidades documentales, defendió la utilización del título formal, es decir del que figura en lugar preferente en el documento que se describe, salvo si era incoherente, inexpresivo, incorrecto, poco conocido, excesivamente largo..., ya que si se daban esas condiciones, el archivero debía elaborar uno "atribuido" que describiera de una forma más exacta la unidad documental. La preferencia por el título formal tendrá consecuencias en las descripciones, pero optar por él o no es una prerrogativa del responsable de la descripción. Si se opta por el título atribuido, la información incluida debe permitir la identificación de la unidad de descripción teniendo en cuenta, en primer lugar, que el principio de pertinencia debe primar sobre el de no repetición de la información. En todo caso "incluirá la información imprescindible para la identificación de la unidad de descripción: tradición y tipología documental, autor, destinatario/beneficiario, materia (persona, lugar o asunto", evitando toda información no

\footnotetext{
${ }^{66}$ Se refiere a los formados por las unidades documentales compuestas y por las unidades documentales simples.

${ }^{67} \operatorname{ISAD}(G)$ : Norma internacional..., p. 21.

${ }^{68}$ J. L. BONAL ZAZO y otros, Manual de descripción multinivel, p. 33.
} 
esencial" 69 . Las similitudes con los "datos internos" que según A. Heredia Herrera se debían recoger en los catálogos cuando describimos documentos son más que evidentes $^{70}$.

Lo interesante es que en la $N E D A$ se recogen ejemplos de descripciones, desde el fondo a las unidades documentales. En las de series, y sus niveles inferiores, el tipo documental aparece reflejado expresamente. Veamos algún ejemplo. En el Archivo de la Nobleza, en el fondo del Archivo de los Duques de Osuna, dentro del Ducado de Gandia, considerado como primera división de ese fondo, se identifica una serie de "Protocolos notariales de Gandia"; una de sus fracciones se denomina "Protocolos notariales de Pedro Belsa" y en ella, como unidad documental compuesta, existe un "Protocolo notarial" que por el campo "fecha" se data en 1458. Como vemos, el tipo documental "protocolo notarial" se ha recogido en el campo "título" en las descripciones realizadas desde serie a unidad documental.

Otro ejemplo. En el Archivo Histórico Nacional de Madrid hay un fondo titulado "Universidad Central". Una de sus divisiones de fondo es la denominada "Facultad de Teología". En ella se distingue una serie de "Expedientes académicos" de la que forma parte, como unidad documental compuesta, el "Expediente académico de Salvador Abad Miras".

Otro caso más. El "Expediente de reparación del Archivo Histórico Nacional de Madrid", definido como unidad documental compuesta, se clasifica en la fracción de serie denominada "Expedientes de Madrid", de la serie "Expedientes de obras", generada por el Negociado de Construcciones Civiles ( $2^{\mathrm{a}}$ división de fondo), adscrito a la Dirección General de Instrucción Pública ( $1^{\mathrm{a}}$ división de fondo) perteneciente al Ministerio de Fomento (fondo conservado en el Archivo General de la Administración de Alcalá de Henares).

En la Norma de descripción archivística de Cataluña (NODAC) 2007, y entre las reglas generales que afectan al elemento "Título", podemos resaltar la que indica que se debe priorizar el título formal sobre el atribuido, "sobre todo en documentación antigua, en la cual los títulos acostumbran a ser bastante explícitos" o "cuando no haya garantías de rigor en el momento de asignar un título atribuido, ya sea porque se desconocen las características de la unidad de descripción, o bien

\footnotetext{
${ }^{69}$ Norma española de descripción archivística (NEDA) $1^{a}$ versión, p. 7 del Elemento "Títu10 ".

${ }^{70}$ Nuestra maestra, entre los datos internos incluía, además, la data, pero la $\operatorname{ISAD}(G)$ la considera un elemento diferenciado, que no se debe incluir en el "Título".
} 
porque no es factible profundizar en ella"71. La NODAC también se refiere a la necesidad de normalizar mediante un lenguaje controlado "la denominación de las tipologías documentales" (regla general núm. 23) ${ }^{72}$. Y entre las reglas específicas subraya que en el título de las series debe usarse "preferentemente el plural y es aconsejable incluir en el título la tipología jurídica y/o diplomática" (regla específica núm. 5); y en la descripción de las unidades documentales "puede incluirse la autoría del documento, el tipo de documentación, el tipo de tradición documental, la localización, los destinatarios o beneficiarios, la función, la actividad, la materia, el asunto o el tema de los documentos" (regla específica núm. 6).

En la $N O D A C$ se recogen menciones expresas de nombres de series y de unidades documentales. Entre las primeras están los "inventarios y balances", los "expedientes sancionadores en materia de consumo", los "expedientes ${ }^{73}$ de bingos"74 ... y entre los segundos hay descripciones como "Fotografía de los aguaceros del barrio antiguo de Girona", o "Copia del informe entregado al director de la escuela Thau". Entre los ejemplos completos recogidos en el último capítulo de esta norma encontramos la descripción de la serie de "Expedientes de licencia de actividad clasificada" y de otras unidades documentales simples y compuestas. Si nos detenemos en el elemento "Título" de ellas veremos que no siempre se han seguido las reglas generales y específicas ya mencionadas.

En la Norma gallega de descripción archivística (NOGADA) se indica que el objetivo del campo "Título" es "dar un nombre a la unidad de descripción". Tras la distinción ya conocida entre título formal y título atribuido, se añade que el primero puede ser "establecido por el productor en el momento de creación de los documentos, o bien otorgado con posterioridad por el propio productor o por quien le sucedió en la gestión y custodia, antes de su integración en el archivo que realiza la descripción"75.

\footnotetext{
${ }^{71}$ Véase la p. 49 de la Norma de descripción archivística de Cataluña (NODAC) 2007. Este argumento es muy débil. Parece que vienen a decir que si no lo conozco o no lo puedo mejorar es preferible dejarlo como está.

${ }^{72}$ En la NOGADA se incluye una regla similar al establecer que "es conveniente usar un lenguaje controlado previamente definido para las denominaciones, tanto de tipos documentales como de topónimos, materias y autoridades. Véase Norma gallega... febrero 2010, p. 33.

${ }^{73}$ En el texto impreso por un error, posiblemente de imprenta, aparece la palabra "expediente" en singular.

${ }^{74}$ Esta denominación es imprecisa e incorrecta. No puede haber "expedientes de bingos" porque con este enunciado desconocemos su finalidad. Habrá expedientes de autorización, de sanción, de... de bingos.

${ }^{75}$ Norma gallega de descripción archivística (NOGADA): febrero 2010, p. 29.
} 


\section{MARIANO GARCÍA RUIPÉREZ \\ LA DENOMINACIÓN DE TIPOS, SERIES Y UNIDADES DOCUMENTALES EN ESPAÑA...}

Este punto de vista es interesante pero no cabe duda de que hay documentos que tienen títulos formales dados tras su incorporación en el Archivo. En la NEDA se había definido el "Título formal" como el "Título que figura en un lugar preferente de la documentación que se describe" sin indicar si había sido dado por el productor, y sus continuadores, o por la persona que hizo su descripción una vez ingresado en el Archivo, o sus sucesores. También en esta Norma se subraya que si existe en los documentos más de un título formal se optará por el más pertinente y si hay varios que tienen esta consideración "por el coetáneo o por el más próximo cronológicamente a la creación de la unidad que se está describiendo".

En la NOGADA se introduce otra modificación llamativa, la relativa a "Título sistemático". Se entiende necesario para contextualizar la unidad de descripción y con él se establece la posibilidad de que el título de una unidad de descripción "podrá incluir además del nombre o expresión que la identifique, el nombre de las unidades superiores" separando esos elementos con el uso de la barra inclinada (/). Entre los ejemplos que incluyen recogemos dos a continuación. El título sistemático de la serie "Expedientes de apeo" sería: Real Audiencia de Galicia / Audiencia / Justicia y Gobierno / Expedientes de apeo. El título sistemático del documento "Expediente de actividades con motivo de la celebración de la fiesta del árbol, el día 25 de febrero" sería: Ayuntamiento de A Coruña / Servicios / Cultura y funciones públicas / Fiestas, funciones y diversiones públicas / Expedientes de actividades / Expediente de actividades con motivo de la celebración de la fiesta del árbol, el día 25 de febrero.

Entre las reglas específicas recogidas en la $N O G A D A$ se incluye la de que el título de las series y subseries irá preferentemente en plural. Y esto es lo habitual. También aclara que cuando exista una pluralidad de tipos documentales en una misma serie, se atribuirá el título de la misma en la forma que sea pertinente para definir el conjunto. En su aclaración se utilizan como ejemplos de esas series con tipología compartida las siguientes denominaciones: "Expedientes de convenios y conciertos", y "Expedientes de concursos y certámenes". Además se indica que, en el caso de las unidades documentales, su título puede incluir los elementos siguientes: autor, tipo documental, tradición documental, localización, destinatarios o beneficiarios y el asunto. Estos pueden ir colocados en el orden más conveniente de acuerdo con el criterio del centro descriptor y las reglas de descripción multinivel.

En el anexo de los modelos descriptivos completos que tiene la NOGADA, la redacción del campo "Título" adopta el formato indicado de "Título sistemático" arrastrando, por tanto, los títulos que identifican los niveles superiores. Así se 


\section{MARIANO GARCÍA RUIPÉREZ \\ LA DENOMINACIÓN DE TIPOS, SERIES Y UNIDADES DOCUMENTALES EN ESPAÑA...}

describe una serie en el campo "Título" como "Organización Provincial de Trabajos Portuarios de A Coruña / Seguridad e Higiene / Comité de Seguridad e Higiene / Libros de actas", y para describir una de las unidades documentales que la forman se repiten todos los datos pero se añade al final "/ 1979" "76 con lo que se identifica con el Libro de actas de 1979.

\section{Unidad Documental}

\section{1. ÁREA DE IDENTIFICACIÓN}

1.1. Código de referencia: ES GA 15030 ARG 1.3.2 OTPC 4.1.2. 29675/13

1.2. Título: Organización Provincial de Trabajos Portuarios de A Coruña/ Seguridad e Higiene/ Comité de Seguridad e Higiene/Libros de actas/1979

1.3. Datas:

- De producción: 1979-01-01/1979-12-31

1.4. Nivel de descripción: Unidad documental

1.5. Volumen y soporte: 243 fol.

\section{2. ÁREA DE CONTEXTO}

2.1. Nombre del productor: Organización Provincial de Trabajos Portuarios de A Coruña//Comité de Seguridad e Higiene ${ }^{38}$

\section{6. ÁREA DE NOTAS}

6.1. Notas:

- A Alcance y contenido. Esta unidad incluye además otros libros de actas: Libro de actas de la Comisión Delegada para Asuntos Laborales 1975, Libro de actas de la Subcomisión de Tráfico Comercial 1975/1976, Libro de actas de la Comisión Delegada de Asuntos Laborales de Tráfico Pesquero 1977/1979, Libro de actas de la Comisión Delegada de Asuntos Laborales de Tráfico Comercial 1979.

Descripción de una unidad documental publicada en la NOGADA, 2010.

En otros ejemplos de esta misma Norma se repite el nombre dado a la serie cuando se describe la unidad documental. Es el caso siguiente: "Delegación de Hacienda de Vigo / Administración / Contribución Territorial / Registro fiscal de edificios y solares / Registro fiscal de edificios y solares del término municipal de Lavadores, parroquias de Beade y Bembrive"77. Los hay que mencionan su condición de "Expedientes" al describir la serie y no cuando descienden a la unidad documental, o al contrario ${ }^{78}$. Solo no arrastran la descripción de los niveles supe-

${ }^{76}$ Norma gallega..., pp. 109-110.

${ }^{77}$ Norma gallega..., p. 115.

${ }^{78}$ Norma gallega..., p. 119. El título sistemático de la serie recogida en esta página termina con "/ Licencias de obras particulares". Y cuando mencionan una de sus unidades documentales concluyen su largo título con “/ Expediente para construir un desván...”. En el ejemplo de la p. 106 el título sistemático de la serie concluye con "Expedientes contencioso-administrativos" y el de la unidad documental comienza con "Arturo Hermida Astray contra la resolución...". 
riores al describir un documento de la colección de pergaminos del Archivo del Reino de Galicia ${ }^{79}$.

Los redactores de la NOGADA han constatado que, con la descripción multinivel, cuando se describe una unidad documental concreta puede perderse información por lo que con su aportación de "Título sistemático" queda patente la vinculación entre los distintos niveles descriptivos. Esto choca con posturas como la defendida en la $N O D A C$ en la que se señala que debe evitarse repetir información, cuando ésta se puede heredar de todos los niveles precedentes. Y entre medias, comprobamos que en la $N E D A$ se establece que el principio de pertinencia debe primar sobre el de no repetición de la información.

Está claro que cuando nos referimos a una serie o a una unidad documental concreta, aislada, sin tener el "paraguas" de la descripción multinivel, debemos utilizar elementos que permitan su fácil identificación. Y en los ejemplos recogidos en las normas mencionadas esto no siempre es posible ya que para lograrlo debemos apoyarnos en los títulos de las agrupaciones superiores, como han entendido los archiveros responsables de la NOGADA. Otra cosa es que ese tipo de redacción, la que se ofrece en esa Norma en el campo "Título atribuido", sea o no atractiva. Y esta problemática queda claramente expuesta cuando se realizan estudios de series para su valoración y selección, o cuando se cita un documento concreto por un investigador en un texto científico. ¿Podemos denominar un documento como "protocolo notarial" sin más como ocurre con un ejemplo de la NE$\mathrm{DA} ?^{80}$.

La apuesta por el "Título formal" que hace la $\operatorname{ISAD}(G)$, y con ella las normas que la han desarrollado, cuando se hacen descripciones de unidades documentales, puede que no sea lo más correcto ya que no son nada uniformes. Y si queremos avanzar en la normalización es evidente que debemos apostar por los títulos atribuidos realizados con rigor, sin que renunciemos a recoger los "títulos formales" que pueda tener un documento en otros elementos de la Norma.

Antes de seguir avanzando en nuestra exposición es preciso recapitular algunas de las conclusiones ya indicadas:

1. La identificación documental se basa en la descripción y ésta se concreta en la denominación. El nombre dado a las distintas agrupaciones documentales tendrá una gran incidencia en las funciones archivísticas. Las

\footnotetext{
${ }^{79}$ Norma gallega..., p. 148.

${ }^{80}$ Recordemos que en la $N O G A D A$, en uno de sus ejemplos, si no se arrastrara la descripción de los niveles superiores una unidad documental se denominaría "1979”, sin más.
} 
descripciones que hemos realizado de los documentos, concretadas en el nombre con el que los hemos identificado, serán básicas para su clasificación.

2. El nombre del tipo documental es imprescindible para denominar la unidad documental y la serie de la que forma parte.

3. El término "tipo documental" irrumpe con fuerza en la archivística española por influencia de la obra de T. Schellenberg, Técnicas descriptivas de archivos, aparecida en 1961, aunque ya lo venían utilizando con anterioridad los diplomatistas en sus estudios, al igual que otros archiveros españoles. Estos últimos preferían la expresión "clase de documentos".

4. Por "tipo documental" debemos entender un modelo que permite reconocer a unidades documentales semejantes, aunque esto no siempre ha estado tan claro al ser un concepto pobremente definido. Archiveras como Vicenta Cortés y Antonia Heredia han ayudado enormemente a su clarificación.

5. En España han habido dos claras corrientes a la hora de incluir la tipología en la descripción de las unidades documentales. Para un grupo de teóricos era un dato secundario y accesorio, mientras que para otros es esencial. La $\operatorname{ISAD}(G)$ ha dado la razón a estos últimos.

6. En la $\operatorname{ISAD}(G)$, y en las normas que la han desarrollado, el elemento "Título" es el que se destina a la denominación de la unidad de descripción.

7. En la descripción de las unidades documentales, siguiendo la $\operatorname{ISAD}(G)$, en el campo "Título" pueden recogerse el nombre del autor, el tipo documental y el tema, entre otros datos. La NEDA ha sancionado la inclusión en el campo "Título" de los relativos a la tradición y tipología documental, autor, destinatario y materia, tal y como se ha venido haciendo en España desde hace siglos.

8. En la teoría archivística española de desarrollo de la $\operatorname{ISAD}(G)$, además del título formal y del título atribuido, se han utilizado otros conceptos como el de título oficial y el de título sistemático.

9. Los ejemplos de descripciones de unidades documentales, aportados en las normas españolas, distan mucho de estar normalizados. Hay ejemplos que arrastran la tipología desde la denominación de la serie hasta la unidad documental. Otros al incluirla en la serie ya no la recogen en la unidad documental, o al contrario.

10. Avanzamos que, frente a los que defienden la preferencia del título formal en las descripciones de las unidades documentales, tal y como esta- 


\section{MARIANO GARCÍA RUIPÉREZ \\ LA DENOMINACIÓN DE TIPOS, SERIES Y UNIDADES DOCUMENTALES EN ESPAÑA...}

blece la $\operatorname{ISAD}(G)$, somos partidarios de priorizar el título atribuido siempre que sea el resultado de un análisis científico del documento realizado con los métodos archivísticos conocidos. Para los documentos públicos ese título atribuido debe coincidir con el título oficial dado por el legislador, si es que lo tiene.

\section{EL TIPO DOCUMENTAL: DELIMITACIÓN DEL CONCEPTO}

La materialización de la producción documental se plasma en las unidades documentales que siguen unos determinados modelos, denominados tipos, según su finalidad. Las variaciones en la denominación de los tipos documentales están condicionadas, también, por la evolución de las culturas que los utilizan y de las lenguas en las que se redactan. Es decir, el tipo utilizado en una unidad documental concreta realizado para un determinado fin puede haber recibido otros nombres en épocas anteriores, aunque su cometido no haya cambiado. Y los mismos tipos documentales, con idéntico contenido y parecida estructura, pueden recibir denominaciones distintas según el país en el que se utilizan, aunque se use la misma lengua. Veamos ejemplos de uno y de otro utilizando tipos documentales comunes.

La Ley 30/1992 de Régimen Jurídico de las Administraciones Públicas y de Procedimiento Administrativo Común, que regula esta faceta en España, determina que los ciudadanos pueden dirigirse a los órganos administrativos mediante solicitudes, escritos y comunicaciones. El contenido informativo de una "solicitud" está recogido en el art. 70 de esa $L e y^{81}$ y en él también se determina que las Administraciones Públicas deben establecer modelos normalizados de solicitudes cuando se trate de procedimientos que impliquen la resolución numerosa de una serie de procedimientos. Pero en la primera Ley de Procedimiento Administrativo, aprobada en España en 1958, ya se había indicado que cualquier persona, natural o jurídica, podía dirigir instancias o peticiones a las autoridades y organismos de la administración del Estado. El contenido de una "instancia" quedó establecido en el art. 69 de esa Ley ${ }^{82}$, y era prácticamente el mismo que el dado a las solicitudes tres décadas después. Es decir, lo que en 1958 era una "instancia" o "petición"

${ }^{81}$ Ley 30/1992, de 26 de noviembre, de Régimen Jurídico de las Administraciones Públicas y del Procedimiento Administrativo Común, en Boletín Oficial del Estado (=BOE), núm. 285, de 27 de noviembre de 1992, p. 40311.

${ }^{82}$ Ley de 17 de julio de 1958 sobre Procedimiento Administrativo. Véase el BOE, núm. 171, de 18 de julio de 1958, p. 1282. 


\section{MARIANO GARCÍA RUIPÉREZ \\ LA DENOMINACIÓN DE TIPOS, SERIES Y UNIDADES DOCUMENTALES EN ESPAÑA..}

pasó a denominarse "solicitud" con la puesta en vigor de la ley mencionada de 1992. Y así se conocen y utilizan en la actualidad.

Pero estos cambios no se hacen de la noche a la mañana. Hasta entrado el siglo XX el documento más comúnmente utilizado por los ciudadanos para dirigirse a la Administración recibió el nombre "instancia" 83 o "petición" 84 que paulatinamente había ido sustituyendo al de "súplica" 85 a lo largo del siglo XIX. Los términos de "memorial" 86 y "representación" 87 , que servían para designar una petición razonada o motivada, entraron en desuso también conforme avanzaba ese mismo siglo. Está claro, pues, que a lo largo de los siglos el mismo tipo documental ha recibido distintas denominaciones y en esos cambios ha tenido mucho que ver la normativa aprobada por la Administración. Es más, una misma acción o actividad se ha podido concretar en un tipo documental que ha recibido dos denominaciones coetáneas, o no. Lo hemos visto con "petición" y "pedimento". Pero hay otros casos, como "súplica" y "suplicación”, "nota” y "anotación”, "pro-

${ }^{83}$ En 1925, en el tomo correspondiente de la Enciclopedia Universal Ilustrada, publicada por Espasa editores, figura que "instancia" en el ámbito administrativo es el "escrito en el que se pide algo que se cree justo".

${ }^{84}$ Los términos "petición" y "pedimento" se utilizaban en la administración de justicia como sinónimos desde hacía siglos. El toledano Sebastián de Covarrubias, en su Tesoro de la Lengua castellana o española, publicado en 1611, indicó que una petición era "la demanda o por palabra o por escrito". Como "escrito con que se pide jurídicamente ante el juez" fue definido por la Real Academia Española en su Diccionario de la Lengua castellana, conocido también como Diccionario de Autoridades, editado en seis tomos entre 1726 y 1739, indicando que "pedimento" era "lo mismo que petición". Ya en el siglo XIX se extendió a otros campos del derecho administrativo al entenderse como cualquier escrito "en que se hace una petición". Sobre los pedimentos existe un breve trabajo colectivo que puede resultar de interés. Nos referimos al texto "Una aportación al estudio tipológico de la documentación judicial del Antiguo Régimen: los pedimentos", en Actas de las primeras Jornadas sobre Metodología para la Identificación y Valoración de Fondos Documentales de las Administraciones Públicas: (Madrid, 20, 21 y 22 de marzo de 1991), Madrid, 1992, pp. 139-149.

${ }^{85}$ Esta, junto con "suplicación" se seguía utilizando por entonces en derecho procesal. Ya recoge estos términos Sebastián de Covarrubias en 1611. Para él una "súplica" era el "memorial que se da al Papa, etc.", mientras que "suplicación" era el "memorial que se da suplicando". En el siglo XVIII se entendía por "suplica", según la Real Academia Española, "el memorial o escrito con que se suplica".

${ }^{86}$ En el Tesoro de la Lengua... de Sebastián de Covarrubias figura que un "memorial” es la "petición que se da al juez o al señor para recuerdo de algún negocio". En 1732, en el tomo III del Diccionario de Autoridades, se indica que se llama también "memorial" al "papel o escrito en que se pide alguna merced o gracia, alegando los méritos o motivos en que funda su razón".

${ }^{87}$ Sebastián de Covarrubias no recoge este término como tipo documental por lo que es factible pensar que empezara a utilizarse más asiduamente ya avanzado el siglo XVII. Sí aparece en el Diccionario de Autoridades entendido como "la súplica o proposición motivada, que se hace a los Príncipes y superiores". 


\section{MARIANO GARCÍA RUIPÉREZ \\ LA DENOMINACIÓN DE TIPOS, SERIES Y UNIDADES DOCUMENTALES EN ESPAÑA..}

puesta" y "proposición”, “credencial” y "acreditación”, etcétera. Y no siempre han tenido la misma finalidad, como ocurre con "informe" e "información" 88.

La irrupción de tipos nuevos como consecuencia de una nueva administración tiene muchos ejemplos. En España, la llegada de los Borbones en el siglo XVIII motivó la aparición de tipos documentales hasta entonces inexistentes como es el caso de las reales órdenes ${ }^{89}$, o la utilización de palabras tomadas del francés para distinguir tipos ya conocidos. Como ejemplo de esto último traemos a colación el término "reglamento" 90 que empezó a extenderse en ese siglo frente al tradicional término castellano de "ordenanza" u "ordenación". Todavía en la actualidad se siguen utilizando indistintamente sin que los estudiosos hayan conseguido encontrar diferencias tipológicas que distingan a las ordenanzas de los reglamentos.

Advertimos al principio de este apartado que el mismo tipo documental podía ser denominado de distinta manera también según el ámbito geográfico en donde fuera utilizado. Y el ejemplo más claro es el documento que acredita la identidad personal. En España, en la actualidad, se denomina como "Documento Nacional de Identidad"91, al igual que en Argentina o Perú. Pero en otros países de habla hispana recibe o ha recibido otros nombres. Es el caso de "Cédula de Identidad" (Bolivia, Chile, Costa Rica, Nicaragua, Uruguay y Venezuela), "Cédula de Ciudadanía" (Colombia y Ecuador), "Documento Único de Identidad" (E1 Salvador), "Documento Personal de Identificación" (Guatemala), "Tarjeta de Identidad" (Honduras), "Cédula de Identidad Personal” (Panamá), "Cédula de Identidad Civil" (Paraguay), "Cédula de Identidad y Electoral” (República Dominicana)... En Portugal se denomina como "Cartão de Cidadão" y en Brasil como "Documento Nacional de Identificação Civil, Carteira de Identidade o Registro Geral".

${ }^{88}$ En el Diccionario de Autoridades figura "informe" como "el mismo hecho de informar, u dar noticia de alguna cosa" y "en lo forense significa la oración que hace el abogado, en hecho y derecho de la causa que defiende". Para S. de Covarrubias, en 1611, era "el memorial que da información". Por "informaciones" según el primer Diccionario se entendía "en lo forense las diligencias jurídicas que se hacen de qualquier hecho u delito" y "las diligencias secretas, que se hacen de la calidad y nobleza de alguno, en orden a conferirle algún oficio, dignidad o insignia".

89 J. J. REAL DÍAZ, Estudio diplomático del documento indiano, $1^{\text {a }}$ reimp., Madrid, 1991, pp. 200-201.

${ }^{90}$ En el Diccionario de Autoridades se recoge la voz "reglamento" entendida como "la instrucción por escrito que se da para la dirección o gobierno de alguna cosa". Sebastián de Covarrubias no recogió ese término en su Tesoro...

${ }^{91}$ Coloquialmente este documento recibe el nombre de "Carnet de Identidad". También es bastante común que se denomine utilizando las letras iniciales de las palabras principales, es decir DNI. 


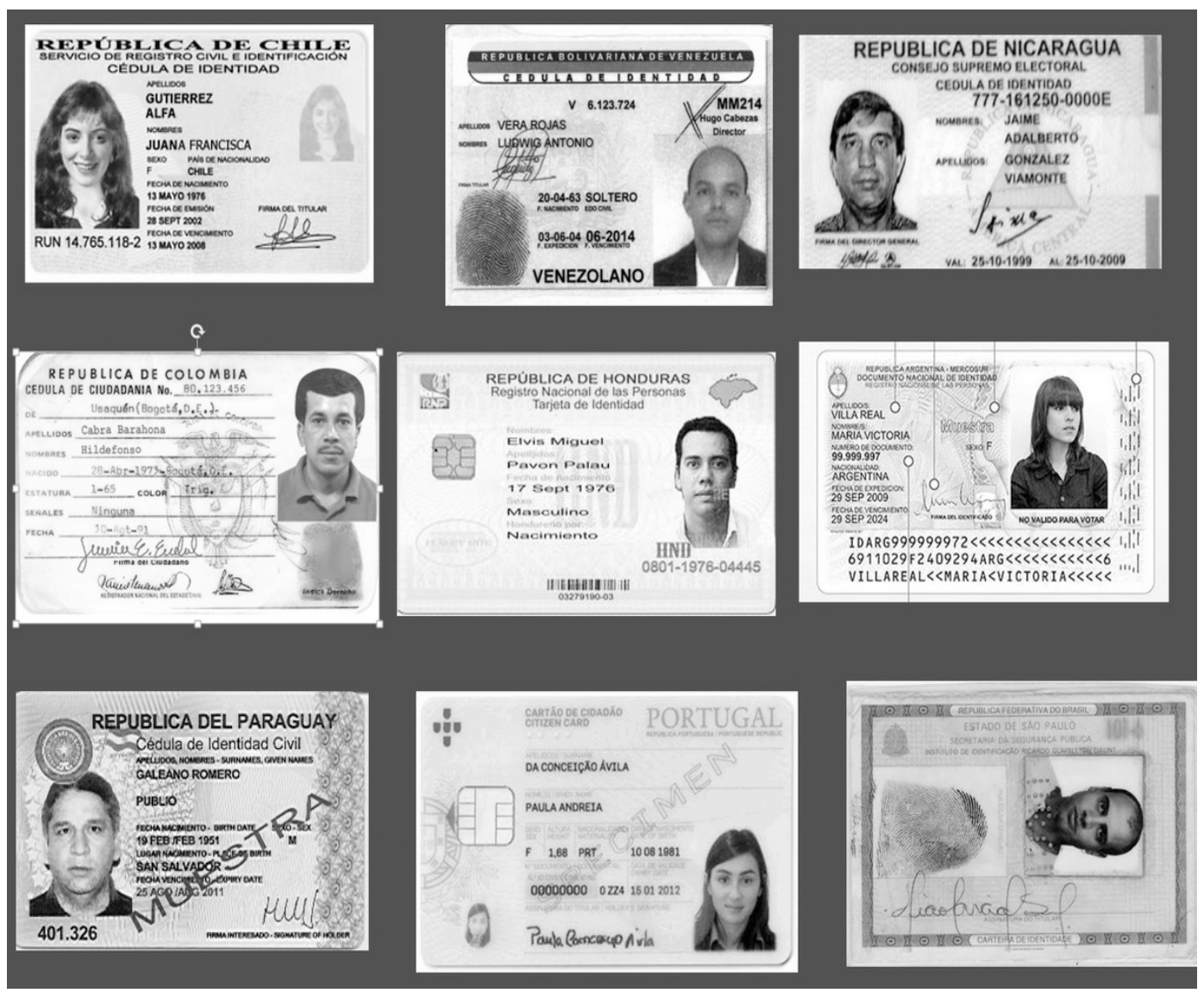

El carnet de identidad en otros paises.

La denominación de estos tipos documentales en cada país ha podido sufrir variaciones a lo largo del tiempo aunque su contenido informativo haya sido siempre muy similar. De nuevo el "Documento Nacional de Identidad" español nos puede ser muy útil. Fue creado por Decreto de 2 de marzo de $1944^{92}$ y aunque ha tenido desde entonces distintos modelos y soportes sigue manteniendo esta denominación hoy día. Pero en España habían existido con anterioridad documentos con contenido y funciones similares tales como las "Cédulas de vecindad" (1854-1870), las “Cédulas de empadronamiento" (1870-1874) y las “Cédulas personales" (1874-1944), a los que podemos unir los "Pasaportes para lo interior" (desaparecidos en 1854) y las "Cartas de seguridad" (1824-1835) ${ }^{93}$.

92 BOE de 21 de marzo de 1944, p. 2346.

93 Sobre sus características puede verse el estudio de Mariano García Ruipérez y Juan Carlos Galende Díaz, "Los pasaportes, pases y otros documentos de control e identidad personal en España durante la primera mitad del siglo XIX. Estudio archivístico y diplomático", Hidalguía. La Revista de Genealogía, Nobleza y Armas, LI (2004), pp. 113-144 y 169-208. 


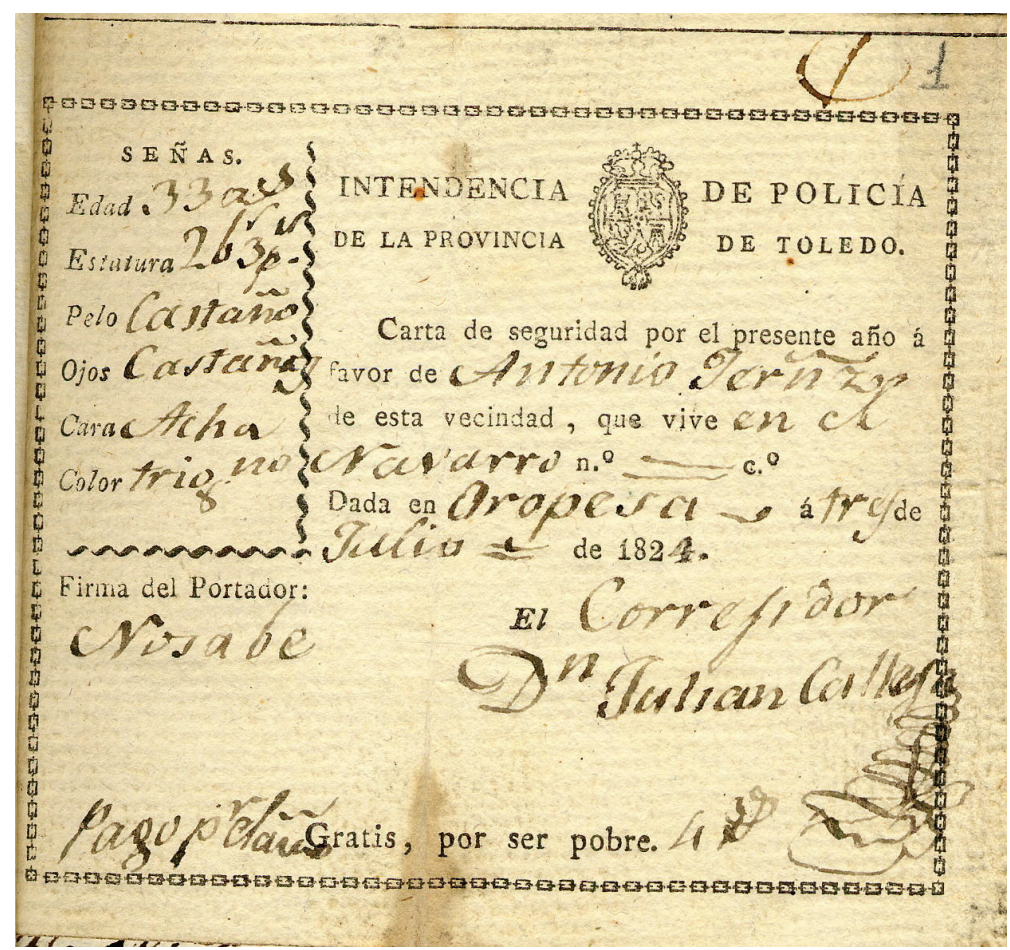

Carta de seguridad del año 1824.

Incidimos en que lo que caracteriza a un tipo documental es su contenido informativo que está relacionado con su finalidad, con su objeto. $\mathrm{Y}$ ese contenido informativo está plasmado siguiendo una determinada disposición o estructura lo que también facilita su identificación y distinción. Pero cambios en ella, en el diseño de esa estructura, no tienen por qué implicar un nuevo tipo documental que lleve aparejado una nueva denominación. Es decir, aunque el soporte, el formato y la disposición informativa sean modificados puede seguir siendo el mismo tipo si así lo decide quien tiene autoridad para ello. Veamos ahora dos ejemplos sencillos que nos ayudan en nuestra exposición.

Los pasaportes para viajar de unos países a otros tienen una larga existencia, de varios siglos. En las primeras décadas del siglo XIX solían extenderse en una hoja de grandes dimensiones (de mas de 400 x $300 \mathrm{~mm}$ ) en cuyo reverso se recogían de forma manuscrita los vistos o "visados" de las autoridades a las que habían sido mostrados, autenticados con sus correspondientes sellos entintados. En Francia se denominaban "Passeport a l'Etranger", en Italia "Passaporto" y en España "Pasaporte" 94 . Eran expedidos por las autoridades gubernativas de cada país

${ }^{94}$ En el tomo V del Diccionario de Autoridades, publicado en 1737, se dice que un "passaporte" es la "licencia u despacho por escrito, que se da para poder passar libre y seguramente de un Reino a otro, u de una a otra parte". Para Sebastián de Covarrubias, en 1611, era "la licencia 


\section{MARIANO GARCÍA RUIPÉREZ \\ LA DENOMINACIÓN DE TIPOS, SERIES Y UNIDADES DOCUMENTALES EN ESPAÑA...}

para permitir a sus titulares viajar al extranjero. Referir las modificaciones habidas en este tipo de documentos requiere un estudio tipológico, posiblemente país por país. Obviamente en esos pasaportes de principios del siglo XIX no había fotografías ni estaban reproducidas las huellas dactilares, ni... Pero, es más, durante el siglo XX fue habitual su expedición en forma de libreta, formada por uno o varios cuadernos con tapas de cartulina de determinados colores y de una extensión variable (de decenas de hojas) ${ }^{95}$. En el siglo XXI muchos países han adoptado el pasaporte electrónico que incorpora un chip embebido en su portada con datos sensibles de su titular. Así ocurre en España desde el 28 de agosto de 2006. Lo interesante es que a pesar de estos cambios, que han afectado a su estructura informativa y a su formato, se siguen denominando "pasaportes" y además es un término generalizado en todo el mundo, con un contenido informativo muy similar.

El otro ejemplo que queremos comentar es el del permiso para conducir vehículos automóviles que también es un tipo documental común, presente en todos los países. Su origen es mucho más reciente pues en la mayoría de las naciones surgió ya en el siglo XX lo cual es obvio si tenemos en cuenta la invención de los motores de combustión. Es un documento público que autoriza a su poseedor para conducir vehículos de tracción mecánica, bajo determinadas condiciones. En España se denomina oficialmente "Permiso de conducción", aunque coloquialmente se conoce como "Carnet de conducir". Durante su existencia ha tenido diferentes modelos establecidos por las autoridades en normativas específicas. Por citar solo las más recientes, en $1997^{96}$ se aprobó un modelo, apto para su uso en los países de la Comunidad Económica Europea (CEE), realizado en una cartulina de color rosa, de unas dimensiones concretas (102 $\mathrm{mm}$ de alto por $222 \mathrm{~mm}$ de ancho), que generalmente se conservaba plegado en forma de tríptico. El contenido de su anverso y reverso estaba dividido en tres partes, formando así seis páginas. En ellas se distribuía la información precisa del "permiso de conducción" (datos de identificación del titular, categorías de vehículos para los cuales era válido el permiso, el periodo que abarcaba esa validez, etc.). En el año 2004 se

para poder pasar alguna cosa vedada por los puertos". En poco más de un siglo su finalidad se había ampliado notablemente, de las mercancías a las personas, de los puertos a las fronteras.

${ }^{95}$ En España en las últimas décadas han tenido unas dimensiones de 123 x $85 \mathrm{~mm}$ (altura por base) y están formados por 32 páginas.

96 Este modelo está recogido en el Real Decreto 772/1997, de 30 de mayo, por el que se aprueba el Reglamento General de Conductores. Véase el BOE, núm. 135, de 6 de junio de 1997 , pp. 17374-17375. 
adoptó en España un modelo alternativo de permiso de conducción ${ }^{97}$, aprobado por la CEE, expedido sobre una tarjeta plástica con la información distribuida en su anverso y reverso y con unas dimensiones reducidas de tan solo 55 x $85 \mathrm{~mm}$ (altura por base). Este modelo sustituiría definitivamente al establecido en 1997 con la aprobación de un nuevo Reglamento General de Conductores en el año $2009^{98}$. Es decir, en apenas unos años su formato y soporte han sufrido importantes cambios sin que haya implicado alteraciones en la denominación del tipo documental. Por cierto que en ella no existe el mismo consenso que para los pasaportes. El permiso de conducción es denominado en Italia "Patente di guida", en Francia "Permis de conduire", en Gran Bretaña "Driving licence", en Portugal "Carta de conduçao", etcétera. En países de habla hispana se conocen como "Licencia de/para conducir", "Licencia de manejo" e incluso tienen denominaciones más singulares como ocurre con el "Brevete" que autoriza a conducir automóviles particulares en Perú.
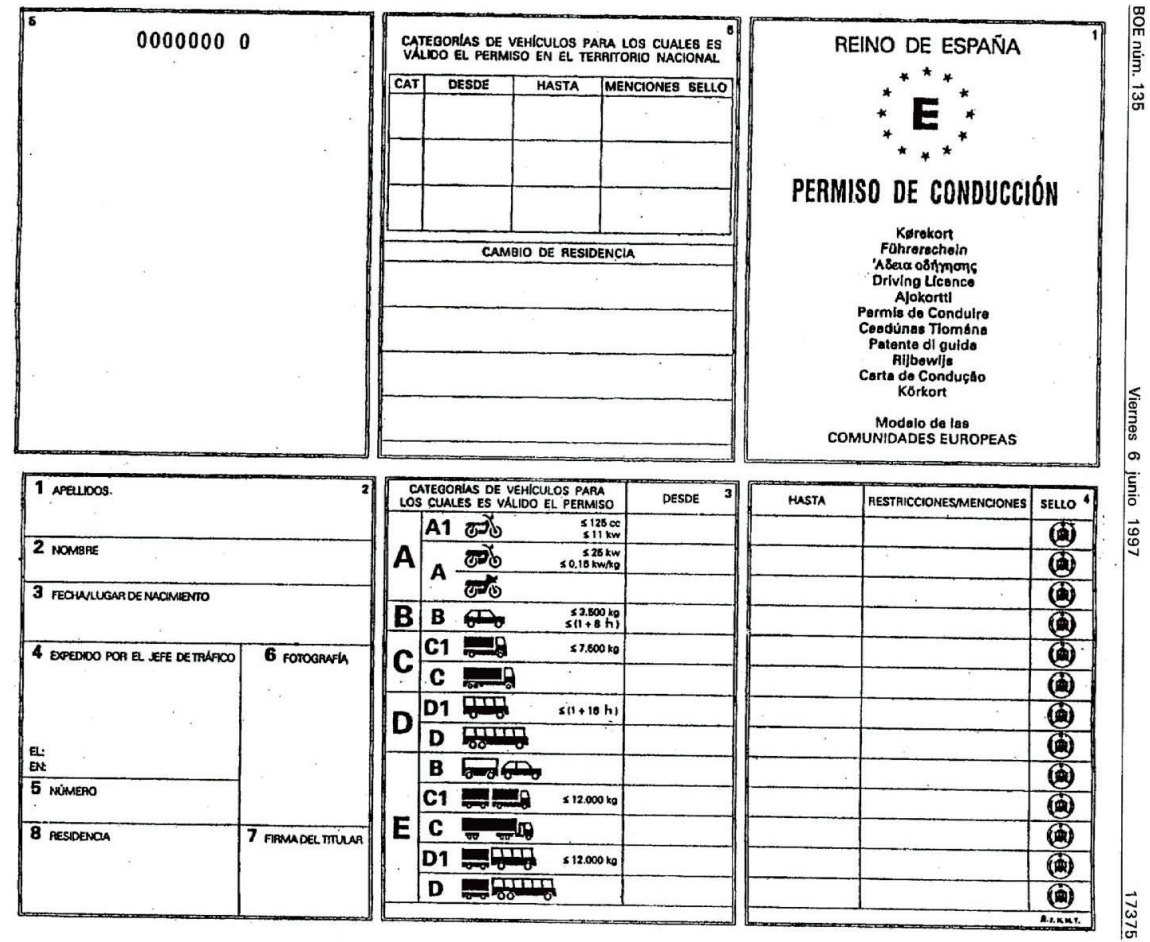

Modelo de permiso de conducción establecido en España en 1997.
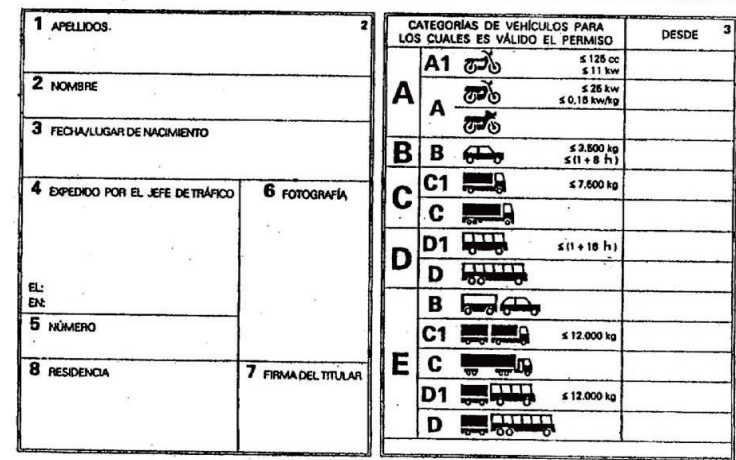

${ }^{97}$ Reproducido en el Real Decreto 1598/2004, de 2 de julio, por el que se modifica el Reglamento General de Conductores, aprobado por el Real Decreto 772/1997, de 30 de mayo., en el $B O E$, núm. 173, de 19 de julio de 2004, pp. 26195-26196.

${ }_{98}$ El modelo de carnet de conducir vigente en España está incluido en el Real Decreto $818 / 2009$, de 8 de mayo, por el que se aprueba el Reglamento General de Conductores. Véase el $B O E$, núm. 138, de 8 de junio de 2009, páginas 48112-48113. 


$\frac{\text { BOLETÍN OFICIAL DEL ESTADO }}{\text { Núm. } 138}$

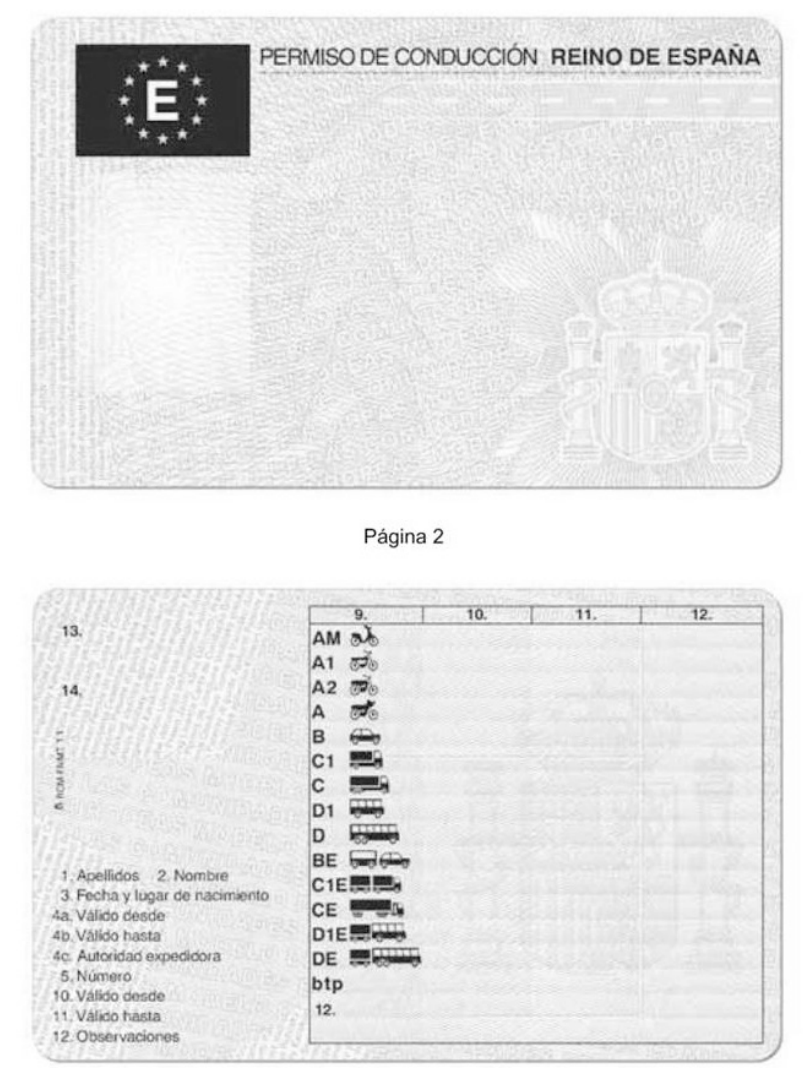

Modelo de permiso de conducción establecido en 2009.

Ya hemos dejado claro nuestro parecer de que por "tipo documental" podemos entender un modelo de unidad documental que se distingue por unas características físicas e intelectuales comunes ${ }^{99}$. Pero las primeras no son determinantes ya que pueden sufrir grandes variaciones, aunque ayudan notablemente a identificar ese modelo en los periodos en los que están vigentes. Lo fundamental de un tipo documental es su finalidad, su objeto, y esa finalidad, que no varía, se articula y se fundamenta en sus características intelectuales que quedan recogidas en su contenido informativo y que generalmente responden a las preguntas para qué, por quién, para quién, cómo, dónde y cuándo.

[Continuará en el número siguiente].

${ }^{99}$ Para nuestros compañeros de la CNEDA el modelo se distingue por unas "características físicas o intelectuales". Pero creemos que las características físicas por sí solas no distinguen un tipo documental. 